\title{
Model coupling for environmental flows, with applications in hydrology and coastal hydrodynamics ${ }^{1}$
}

\author{
Rachid ABABOU, Khalil ALASTAL, Dominique ASTRUC, \\ Ahmad AL-BITAR ${ }^{2}$, Manuel MARCOUX, Yunli WANG ${ }^{3}$
}

Institut de Mécanique des Fluides de Toulouse, Université de Toulouse / INPT-UPS \& CNRS, IMFT, 1 Allée du Professeur Camille Soula, F-31400 Toulouse, France.E-mail: ababou@imft.fr

\begin{abstract}
The aim of this paper is to present an overview of "model coupling" methods and issues in the area of environmental hydrodynamics, particularly coastal hydrodynamics and surface/subsurface hydrology. To this end, we will examine specific coupled phenomena in order to illustrate coupling hypotheses and methods, and to gain new insights from analyses of modelling results in comparison with experiments. Although this is to some extent a review of recent works, nevertheless, some of the methods and results discussed here were not published before, and some of the analyses are new. Moreover, this study is part of a more general framework concerning various types of environmental interactions, such as: interactions between soil water flow (above the water table) and groundwater flow (below the water table); interactions between surface and subsurface waters in fluvial environments (streams, floodplains); interactions between coastal flow processes and porous structures (e.g. sea-driven oscillations and waves through sand beach or a porous dike); feedback effects of flow systems on the geo-environmental media. This paper starts with a general review of conceptual coupling approaches, after which we present specific modelling and coupling methods for dealing with hydrological flows with surface water / groundwater interactions, and with coastal flows involving the propagation of seawater oscillations through a porous beach (vertically and horizontally). The following topics are treated. (1) Coupled stream-aquifer plane flow in an alluvial river valley (quasi-steady seasonal flow regime), assuming aquifer/stream continuity, and using in situ piezometric measurements for comparisons. (2) Water table oscillations induced by sea waves, and propagating through the beach in the cross-shore direction: this phenomenon is studied numerically and experimentally using a wave canal with an inclined beach equipped with capacitive micro-piezometers. (3) Tidally driven vertical oscillations of water flow and capillary pressure in a partially saturated / unsaturated sand beach column, studied numerically and experimentally via a "tide machine" contraption (described in some detail): the goal is to apprehend the role of capillary effects, and forcing frequency, on the hydraulic response of a beach column forced by tides from below. At the time of this writing, some of the results from the tide machine are being reinterpreted (ongoing work). We also point out a recent study of vertical flow in the beach, which focuses on the effect of intermittent waves in the swash zone, rather than tidal oscillations.
\end{abstract}

Key-words: Model coupling for environmental flows, Surface/subsurface hydrology, Coastal hydrodynamics, Wave canal, Tide machine experiment, Saturated/unsaturated porous beach.

\section{Couplages de modèles pour les écoulements environnementaux, avec applications en hydrologie et en hydrodynamique côtière}

RÉSUMÉ. - Le but de cet article est de présenter une revue synthétique des méthodes et problèmes de couplages dans le domaine de la dynamique des fluides environnementale, et en particulier, en hydrodynamique côtière et en hydrologie de surface / souterraine. Dans ce but, on examinera certains problèmes spécifiques, qui permettront d'illustrer les hypothèses de couplages, et d'approfondir la compréhension des phénomènes couplés à partir d'analyses des résultats de modélisation et en comparaison avec des résultats expérimentaux. Bien que cet article soit en partie une revue de travaux récents, certaines méthodes et analyses des résultats n'ont pas été publiées précédemment. De plus, ce travail s'inscrit plus généralement dans le cadre d'un programme d'étude sur différents types d'interactions environnementales, telles que : interactions entre les écoulements dans les sols (au-dessus de la nappe) et dans la zone saturée des aquifères (au-dessous de la nappe) ; interactions entre les eaux de surface et souterraines dans un environnement fluvial (fleuve et plaine d'inondation) ; interactions entre les écoulements côtiers de pleine eau (mer) et les structures poreuses (e.g., oscillations forcées pénétrant et se propageant à travers une page de sable, une digue portuaire, etc.) ; rétroactions entre écoulements et milieux. Cet article commence par une revue générale des concepts de couplages, après quoi nous présentons certaines méthodes plus spécifiques permettant de coupler (en les simplifiant) les écoulements hydrologiques comportant des interactions entre eaux de surface et eaux souterraines, et les écoulements côtiers impliquant la propagation d'oscillations de l'eau de mer à travers une plage de sable (horizontalement, et verticalement). Les sujets suivants sont traités... (1) Ecoulement plan couplé nappe-rivière dans une vallée alluviale (régime moyen saisonnier quasi-permanent), avec hypothèse de continuité de pression à l'interface nappe/rivière, et en utilisant des mesures piézométriques in situ pour les

1. (Note: this article is an extended English version of the Keynote Lecture Paper delivered by R. Ababou in French at SimHE 2013)

2. Currently at: CESBIO - Centre d'Etudes Spatiales de la BIOsphère, UMR 5126 (UPS-CNRS-CNES-IRD), 18 avenue Edouard Belin, BPI 2801, 31401 Toulouse Cedex 9, France.

3. Currently at: ChongQing Southwest Hydraulic Institute for Waterways, ChongQing Jiaotong University, 107 Dahuang Road, Daping, Yuzhongqu, 400016, ChongQing, China. 
comparaisons. (2) Oscillations de la nappe de plage induites par les vagues, et se propageant à travers la plage de sable dans la direction perpendiculaire à la côte : ce phénomène est étudié numériquement et expérimentalement à l'aide d'un canal à houle contenant une plage inclinée équipée de micro-piézomètres capacitifs. (3) Oscillations tidales de l'écoulement vertical et des profils de pression capillaire dans une colonne de plage partiellement saturée / non saturée soumise à l'effet des marées par sa condition limite inférieure. Ce système est étudié numériquement et expérimentalement grâce à une " machine à marée » (qui est décrite ici en détail). Le but est d'appréhender le rôle des effets capillaires, et de la fréquence du forçage tidal, sur la réponse hydraulique de la colonne de plage partiellement saturée / non saturée. $\mathrm{Au}$ moment de la rédaction de cet article, certains des résultats obtenus par la machine à marée sont en cours de réinterprétation. Nous indiquons aussi l'existence d'une récente étude, en cours de développement, sur l'écoulement oscillatoire vertical dans une colonne de plage non pas sous l'effet des marées, mais sous l'effet des vagues intermittentes qui se produisent dans la zone de swash (jet de rive).

Mots-clés : Couplage de modèles en hydrodynamique environnementale, Hydrologie de surface / subsurface; Hydrodynamique côtière, Canal à houle, Machine à marée, Plage poreuse saturée / non saturée.

\section{INTRODUCTION AND SUMMARY}

This paper is a revised and extended version of the keynote lecture initially presented by the first author, in French, at the SimHE 2013 conference held in Casablanca, Morocco (Ababou 2013). In this extended paper, we describe and analyze several results from collaborative work on coastal hydrodynamics and hydrology, involving the coupling of surface water with groundwater, and the propagation of seawater oscillations through a porous beach. These experimental and numerical studies were conducted at the Institut de Mécanique des Fluides de Toulouse. They involved two research groups (Porous Media "GEMP”, Turbulence Waves Environment "OTE") plus outside collaborations.

Our aim here is to present an overview and a review of "model coupling issues" in the area of environmental hydrodynamics, particularly coastal hydrodynamics and surface/ subsurface hydrology, and to gain new insights from analyses of previously obtained results. Although this is to some extent a review work, some of the results were never published before, and some of the analyses are new.

We are interested generally in the interactions between soil water flow (above water tables) and groundwater flow (below the water table), in the interactions of coastal flow processes with porous structures (e.g. propagation of sea-driven oscillations into porous dikes and beaches), and also, in the interactions between surface and subsurface waters in fluvial environments (streams, floodplains).

In the remainder of this paper, we treat the following topics. We start, in the next section (Section II), with a brief conceptual review of alternative coupling approaches for environmental flow problems. We then study in Section III coupled stream-aquifer flow in an alluvial river valley (quasi-steady seasonal plane flow regime), using in situ piezometric measurements for comparisons. The remaining sections focus on coastal hydrodynamics problems in the presence of porous beaches. Section IV considers the case of a wave canal with an inclined beach at one end, equipped with micro-piezometers. Wave induced oscillations of the water table, propagating in the beach, are studied along the cross-shore direction, experimentally and numerically. Section $V$ considers tidally driven vertical oscillations of water flow and capillary pressure in partially saturated / unsaturated sand beach column. The method used to force the tidal effect is implemented experimentally via a "tide machine" contraption, which is described here in some detail. We present some modeling results and analyses regarding capillary effects on the hydraulic response of the sand beach column, which was the main scientific goal of this tide machine study. Finally, the results obtained for the different applications are recalled and discussed in the conclusive Section VI.

\section{OVERVIEW OF ALTERNATIVE APPROACHES TO MODEL COUPLING}

Let us start with a brief review of conceptual approaches to model coupling. We distinguish:

i. Weak coupling (sequential, unidirectional, or "explicit" coupling) vs. strong coupling (bidirectional, retroactive, or « implicit ») ${ }^{4}$;

ii. Localized coupling (via planar or curved interfaces) vs. spatially distributed coupling in $(\mathrm{x}, \mathrm{y}, \mathrm{z})$ space;

iii. External or code-to-code coupling vs. internal coupling or equational coupling (within a single code).

On the whole, there are many possible methods for coupling different phenomena in a model, because the above categories (i, ii, iii, ...) can be sometimes combined.

Let us consider one example concerning stream-aquifer flow coupling. One popular approach is to implement this coupling via a conductance term proportional to $\left(\mathrm{H}_{\text {AQUIFER }}\right.$ $\left.(\mathrm{x}, \mathrm{y}, \mathrm{z})-\mathrm{H}_{\text {STREAMBed }}(\mathrm{x}, \mathrm{y})\right)$. This coupling term is defined at the stream-aquifer interface, $z=Z_{\text {INTERFACE }}(x, y)$, representing the streambed. Therefore, this method is a type of "localized coupling" (at an interface), and it is also a type of "external coupling" (code-to-code) because the method is more naturally implemented with 2 different codes or modules, one for aquifer flow, the other for stream flow, coupled through the interface.

In contrast, the stream-aquifer coupling approach to be presented in more detail further below is a type of "strong" or "implicit" coupling, based on a pressure continuity assumption at the aquifer/streambed interface. It can also be qualified as "internal" or "equational" coupling. It uses a single model and a single computer code for its implementation.

This is only one example of coupling problem. In this paper, we will also consider an issue that arises in coastal

4. Note: the terms "explicit" and "implicit" are borrowed here from numerical terminology in reference to the well-known discretization schemes, Euler forward (explicit) and Euler backward (implicit). 
and beach hydrodynamics: a modeling strategy is needed for transmitting oscillations from seawater to the porous beach. The goal is to analyze the hydraulic response of the beach forced by seawater oscillations or waves. The beach response being our main focus, the seawater forcing will be simplified as much as possible.

The different possible approaches to coupling were presented in detail in Ababou et al. [2009, 2010], and in other cited references, where coupling issues in various areas of environmental hydrodynamics are discussed.

For example, consider the case of coastal morpho-dynamics, discussed in detail in Ababou et al. 2010 (Section 15.1.4 on Coastal Morphodynamics). Models can be reduced to vertical cross-sections (2DV), or they can represent be vertically integrated processes in the horizontal plane (2DH). Fully 3D model can be obtained by recoupling 2DH and 2DV models. On the other hand, one may consider 3 main types of processes (1: waves or swell; 2: currents; 3 : solid transport) that are coupled according to 6 types of interactions. For instance, $(2) \rightarrow(3)$ refers to the effect of sea waves on the seabed (via stresses exerted on the seabed). This effect could first be ignored in a model (decoupling), then taken into account via a recoupling approach. The whole approach can be viewed as a "divide and conquer" strategy. The need for "recoupling" arises because of previous simplifications.

In harbor problems, one of the objectives is to couple incoming waves (sea swell) with coarse porous structures like breakwaters and dykes, in order to study wave transmission/reflection through these structures. One approach known since the early 1970's (Cross \& Sollitt 1972, Sollitt $\&$ Cross 1972) has been to adapt or generalize the porous medium equation to account for Eulerian and inertial acceleration terms, and then, to analyze the resulting equation in frequency space (e.g. Brossard et al. 2004). For a review and results focused on wave transmission through porous breakwaters, sea Tomasicchio \& D'Alessandro (2013). Other approaches start, rather, with the Navier-Stokes equation and modify it by introducing an internal solid/fluid friction term. For a semi-empirical approach based on measurements interpreted with Navier-Stokes, see for instance Losada et al. (1995).

Other authors have considered coupled phenomena in surface/subsurface hydrology. Ababou et al. (1996, 1998, 2002) studied various subsurface flow problems with coupled saturated/unsaturated zones, and they developed a macro-porous medium concept which comprises two aspects: kinetic aspect for open water (see also a somewhat similar idea in Desai and Li 1983), and dynamical aspect for coarse media (inertial acceleration term). In particular, a fictitious macro-porous medium was used for modeling coupled stream-aquifer connections in vertical crosssection without vertical integration (Ababou et al. 2002). Hinz 1998 studied the effect of unsaturated flow, and of the capillary fringe, on coastal water table dynamics. Horn 2006 studied and reviewed beach groundwater measurements and models devoted to the swash zone. Cao et al. 2010 coupled the Darcy and Stokes flow equations using the Beavers \& Joseph (1967) interface condition between the porous medium and open water. Li et al. 2000 (a, b) modeled groundwater "waves" with a linearized Boussinesq equation (vertically integrated groundwater flow) modified to account for the oscillating free surface, and they matched the groundwater and seaward boundary conditions at the beach face. Gunduz \& Aral (2005) studied and modeled groundwater / river network interactions.
Other authors also addressed physical and numerical aspects of surface / subsurface coupling under various hydrologic situations, e.g.: Larabi \& De Smedt (1997); Sbai et al. (2001); Putti \& Paniconi (2004); Panday \& Huyakorn (2004); Kollet \& Maxwell (2006). Finally, it should also be emphasized that, in many cases, fast flow can take place in the porous media adjacent to the open water bodies (lake, sea, stream). In this case, porous flow is modeled via a revamped version of Darcy's law containing an additional quadratic velocity term to account for inertial effects (e.g. Ababou \& Trégarot 2002). The basic model is named Darcy / Ward-Forchheimer (after Darcy 1856; Forchheimer 1931; Ward 1964).

In this paper, we will focus on just a few environmental flow problems involving coupling:

$\rightarrow$ stream-aquifer flow in an alluvial river valley (quasisteady seasonal plane flow regime);

$\rightarrow$ water level oscillations induced by seawater waves, propagating in a beach water table along the cross-shore direction; and

$\rightarrow$ tidally driven vertical oscillations of flow and capillary pressure in a partially saturated/unsaturated column of beach located sufficiently away from the swash zone.

In these different types of flow problems, we will implement an original coupling approach based on the same general principle, as follows: the coupling is equational; it is encapsulated in a single governing Partial Differential Equation (PDE) with nonlinear and heterogeneous coefficients; it is therefore strongly implicit and retroactive, and finally, it is implemented with a single numerical code. Note: the specifics for each type of coupled flow problem, are discussed further in the respective sections (III, IV, V), and in the conclusive section (VI).

\section{HYDROLOGIC COUPLING: STREAM-AQUIFER FLOW (GARONNE RIVER)}

This section focuses on coupled stream-aquifer flow using a vertically integrated / strong coupling approach. Stream-aquifer flow coupling is illustrated with a case study concerning a stretch of the Garonne river valley and its associated subsurface watertable in the accompanying aquifer. We will summarize previous descriptions of the vertically integrated coupled stream-aquifer approach [Albitar 2007, Ababou \& Al-Bitar 2008, Ababou et al. 2010] and present new results as well.

We consider a typical example of coupled hydrologic flow processes: "stream-aquifer" interactions in a meandering stretch of the alluvial Garonne river valley, comprising the river bed and banks as well as the flood plain, and the associated subsurface water table. The meandering stretch of Garonne river that we are studying here, is located between the cities of Toulouse and Moissac, in the department of Haute Garonne, France.

As observed earlier, the conceptual methods that can be considered for coupling groundwater flow with stream flow are very diverse (see Ababou et al. [2009] and references therein). The method presented here consists in averaging vertically the subsurface flow in the saturated zone of the accompanying aquifer (from bedrock to water table), as well as the free surface flow that occurs in the river bed and flood plain above soil surface (topography) and stream bed (bathymetry). In addition, pressure continuity is assumed at the contact of subsurface/surface waters. This implies that the water table remains connected to the stream 
(or flood plain) water level. Desaturation is not allowed to occur below the river bed or the flood plain: therefore, any retarded vertical flow that could have occurred in the unsaturated zone between streambed and water table is ignored or neglected.

Thus, groundwater flow in the accompanying aquifer is governed by the Dupuit-Boussinesq plane flow model. This model is based on Darcy's head loss law, and it assumes (i) quasi-horizontal flow, (ii) unconfined flow (existence of a water table), and (iii) instantaneous drainage/filling of effective porosity during transient movements of the water table.

Surface flow is also assumed quasi-horizontal (plane flow). Surface flow in the river or flood-plain is governed by the 2D kinematic-diffusive wave equation (PDE), which is a simplified version of the vertically averaged 2D Saint-Venant flow equations (system of PDE's). The kinematic-diffusive wave can be expressed as a $2 \mathrm{D}$ nonlinear transmissivity equation, similar to the Boussinesq groundwater flow equation (Al-Bitar 2007). The reader is also referred to Bedient et al. (2002) for a basic presentation of the kinematic-diffusive wave model in the context of floodplain hydrology.

The two equations, surface and subsurface, are then coupled by combining additively at each point $(\mathrm{x}, \mathrm{y})$ their specific discharge rate vectors $\mathbf{Q}\left(\mathrm{m}^{2} / \mathrm{s}\right)$, as indicated in Fig.1 (a,b). The resulting equations of the coupled flow model are also described below, for the case where the Chezy head loss law is used in the river or floodplain.

The unconfined aquifer is denoted by " $\mathrm{A}$ "; $\eta_{A}(x, y, t)$ is the saturated water depth in the aquifer, $Z_{I N F}(x, y)$ is the elevation of the impervious substratum, and $Z_{S}(x, y, t)$ is the elevation of the free surface in the aquifer (elevation of water table with respect to a fixed reference frame). ${ }^{5}$ The $2 \mathrm{D}$ Dupuit-Boussinesq groundwater flow equations can be written as follows:

$$
\begin{gathered}
\theta_{A} \frac{\partial \eta_{A}}{\partial t}=\operatorname{div}\left(\hat{\mathbf{T}}_{A} \operatorname{grad}\left(\eta_{A}\right)\right)+\operatorname{div}\left(\hat{\mathbf{T}}_{A} \operatorname{grad}\left(Z_{I N F}\right)\right) \\
\hat{\mathbf{T}}_{A}=K_{A} \eta_{A} ; Z_{S}(x, y, t)=Z_{I N F}(x, y)+\eta_{A}(x, y, t)
\end{gathered}
$$

where $\theta_{A}$ is the aquifer effective porosity, and $K_{A}$ its saturated hydraulic conductivity $[\mathrm{m} / \mathrm{s}]$.

The river is denoted by "R" (the "river" can also be a floodplain); $\eta_{R}(x, y, t)$ is the water depth in the river; $Z_{F}(x, y)$ is the elevation of the riverbed ("F" stands for "Fond" in French) but it is also denoted $Z_{S U P}(x, y)$ in the global coupled aquifer/river equations; and $Z_{S}(x, y, t)$ is the elevation of the river's free surface (i.e., river water level with respect to a fixed reference frame). The 2D kinematic-diffusive river flow equations can then be decomposed as follows:

$$
\begin{gathered}
\frac{\partial \eta_{R}}{\partial t}=\operatorname{div}\left(\widehat{\mathbf{T}}_{R} \operatorname{grad}\left(\eta_{R}\right)\right)+\operatorname{div}\left(\widehat{\mathbf{T}}_{R} \operatorname{grad}\left(Z_{F}\right)\right) \\
\hat{\mathbf{T}}_{R}=\frac{C_{\text {chezy }}}{\left\|\nabla Z_{S}\right\|^{1 / 2}} \eta_{R}^{2 / 3} ; Z_{S}(x, y, t)=Z_{F}(x, y)+\eta_{R}(x, y, t)
\end{gathered}
$$

5. Note: because of the assumed continuity between aquifer and river, there is no need to make a distinction between $Z_{S}(x, y, t)$ in the aquifer and $Z_{S}(x, y, t)$ in the river. where $T_{R}$ is the equivalent surface flow transmissivity obtained for the Chezy head loss law, and $\mathrm{C}$ is the Chezy roughness coefficient $\left[\mathrm{m}^{1 / 2} / \mathrm{s}\right]$.

The strongly coupled equations for surface+groundwater flow are then expressed as follows:

$$
\frac{\partial \theta_{e}}{\partial t}=\operatorname{div}\left(\widehat{T}^{\prime} \nabla \eta+\widehat{T}^{\prime} \nabla Z_{I N F}+\widehat{T}^{\prime \prime} \nabla Z_{S U P}\right)
$$

where: $\eta(x, y, t)=\eta_{R}(x, y, t)+\eta_{A}(x, y, t)$;

$$
\begin{gathered}
\theta_{e}(x, y, t)=\theta_{A} \eta_{A}(x, y, t)+\theta_{R} \eta_{R}(x, y, t) \\
\widehat{T^{\prime}}=\omega T_{A}+\lambda T_{R} ; \widehat{T^{\prime \prime}}=\lambda\left(T_{A}+\omega T_{R}\right) \\
\quad \text { if } \eta_{R}=0 \text {, then } \omega=1 \text { and } \lambda=0 ; \\
\text { else: if } \eta_{R} \neq 0, \text { then } \omega=0 \text { and } \lambda=1 .
\end{gathered}
$$

In the coupled mass conservation equation (III.3), it can be seen that there are two distinct nonlinear hydraulic transmissivities T' and T"' (they depend on aquifer and river transmissivities $T_{\mathbf{A}}$ and $\mathrm{T}_{\mathbf{R}}$, given in the previous equations III.1 and III.2). There is however only one unknown variable $\theta_{e}(x, y, t)$, which represents the stock of water in a vertical river/groundwater column at any point $(\mathrm{x}, \mathrm{y})$ and time $(\mathrm{t})$. This model is fully coupled and it has no difficulty dealing with the presence or absence of surface water at any point $(x, y)$.

The advantage of this "strong" coupling approach, for the stream-aquifer system, is that it can be implemented with a single flow model, and a single flow code. In practice, in the numerical implementation, we solve a single vertically integrated equational flow model, governing the water level $\mathrm{Zs}=\mathrm{H}(\mathrm{x}, \mathrm{y}, \mathrm{t})$ in $2 \mathrm{D}$ space and time. This single governing equation is "parametrized" in such a way as to represent either the groundwater flow in the aquifer alone, or the diffusive wave equation for surface flow alone, or both at the same time (in regions where surface and subsurface flow co-exist). In these regions, the river/floodplain flow is directly coupled to groundwater flow in the accompanying phreatic aquifer.

Figure $1(\mathrm{a}, \mathrm{b})$ displays a detailed schematic which explains the principle of this type of stream-aquifer coupling (geometry and equations).

Some of the results obtained for a meandering stretch of the Garonne river, are reproduced in Figures 2, 3, 4, all focusing on a mean seasonal steady state simulation of the coupled stream/aquifer flow (transient simulations of coupled stream/aquifer flow during floods were also conducted but are not shown here).

Thus, Fig. 2 displays the simulated stream/aquifer water levels $\mathrm{H}(\mathrm{x}, \mathrm{y})$ in perspective view. Fig. 3 (left) displays the same simulated stream/aquifer water levels $\mathrm{H}(\mathrm{x}, \mathrm{y})$ in plane view. Fig. 3 (right) shows a detailed view (zoom) of the coupled simulated water levels in a meander, and particularly, around and through a pebble "islet" located in the main stream of the river (near one of the river banks).

Finally, Fig. 4 shows a bar plot comparison of simulated $v s$. experimental piezometric heads, measured in situ on the inner side of a meander (this is not the meander that contains the "islet", but another meander in the same computational domain). Most of the piezometers measure groundwater levels inside the meander. A few of them measure water levels near the edge of the river bank or in the river itself. And a 


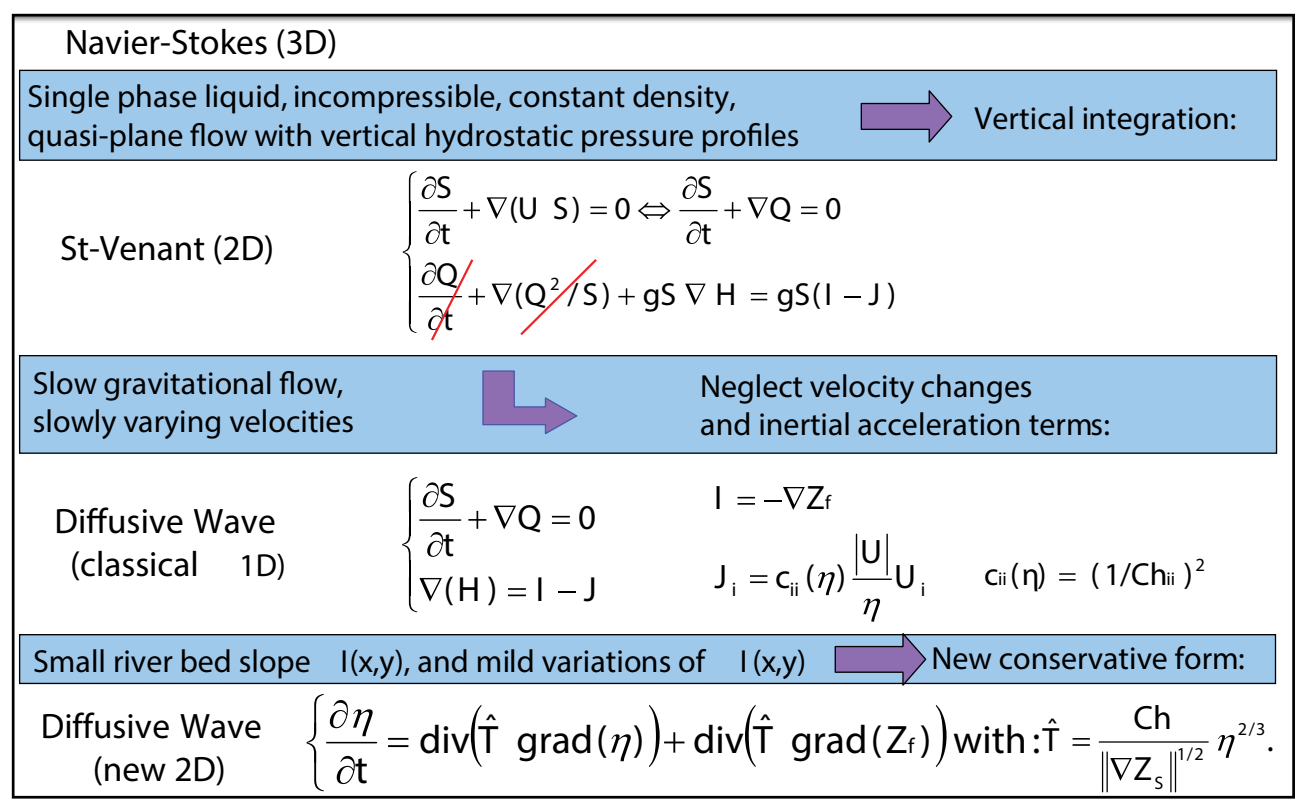

Figure 1(a): Wave diffusion equation for surface water (streams, flood-plains). The scalar equation shown in the lower part is the one used for surface water flow in the $2 D$ module of BIGFLOW. The equation is expressed here in terms of surface water depth $\eta(x, y, t)$. The code finally delivers the output in terms of water level $H(x, y, t)$. See the next sub-figure for the fully coupled version.

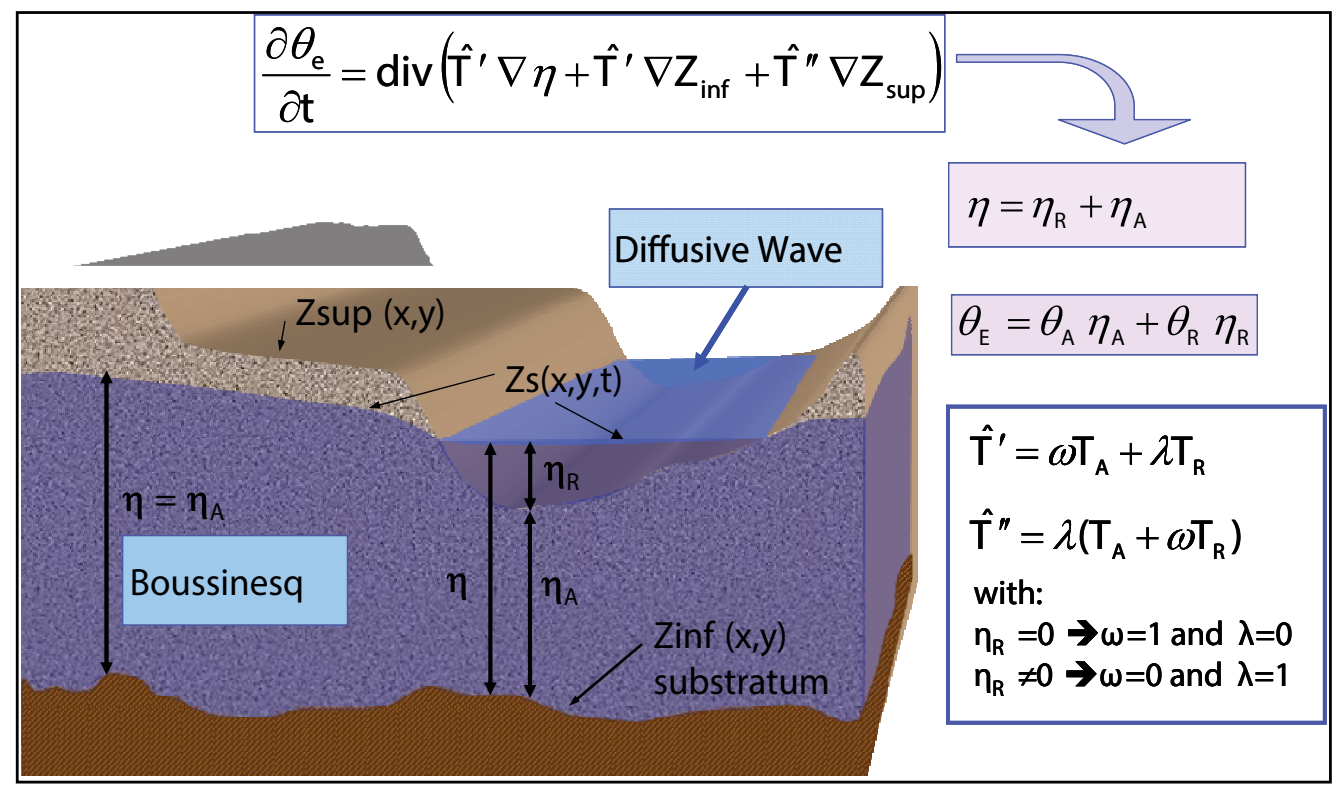

Figure 1(b) : Schematic depicting the equational coupling of the vertically integrated stream-aquifer system. The boxes describe the general form of the fully coupled stream-aquifer equation, as implemented in the BIGFLOW CODE / 2D module (x,y,t). The equations are expressed here in terms of water depths $\eta(x, y, t)$. The code finally delivers the output in terms of water level $H(x, y, t)$, at all $(x, y)$ points of the planar computational domain.

few others (like $\mathrm{N}^{\circ} 27$ ) measure groundwater levels far away from the river meander zone. The piezometric and topographic measurements were collected and interpreted in collaboration with the ECOLAB laboratory in Toulouse, France (J. M. Sanchez-Perez, S. Sauvage, P. Vervier). Concerning specifically the merging of river bathymetry with Digital Elevation Model, and several other data issues, the reader is referred to the thesis of Al-Bitar [2007]. For groundwater and geo-hydrologic data, see also Weng et al. [2003]. The latter work also led to a loose code-to-code coupling of 2D flow in the alluvial plain and of 1D Saint-Venant flow in the
Garonne river on a larger scale (less detailed concerning the meandering river stretch on which we focus here). A brief overview of different coupled modeling approaches, and of the eco-hydrological setup of this stretch of Garonne river, can also be found in Ababou et al. [2006].

Overall, as can be seen from Fig. 4, the simulated piezometric levels $\mathrm{H}(\mathrm{x}, \mathrm{y})$ obtained with our coupled approach compare favorably with in situ measurements. Note that most of the 27 piezometers shown in this comparison are located on the inner left bank of the meander (a few are far outside the meander). 
Steady state results of coupled groundwater/stream flow in the Garonne valley (BIGFLOW-2D module)

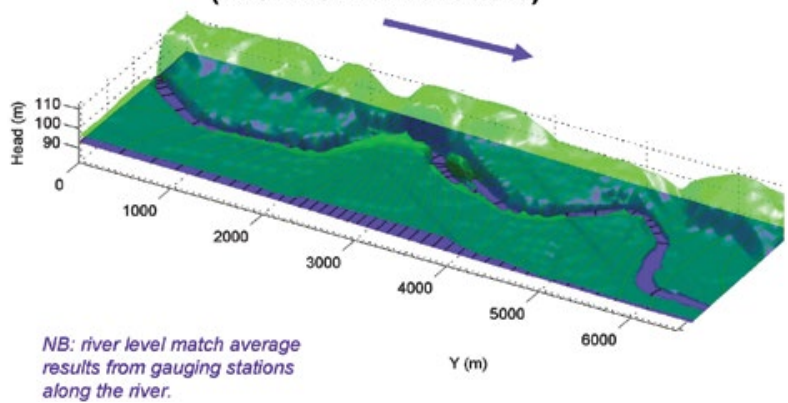

Fig. 2 : Perspective view of coupled stream/aquifer flow in the Garonne river valley, showing topography (green) and the water table in the river and in the accompanying alluvial aquifer (dark blue surface with superimposed piezometric curves). The simulated piezometric heads $H(x, y)$, shown here, were computed by the coupled model for a mean seasonal steady state. The dark blue water table is continuous with the surface water table (per our coupling assumptions).

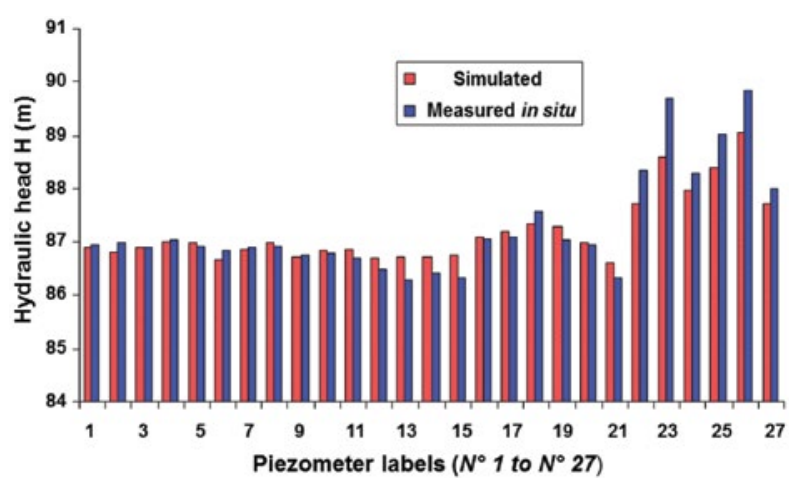

Fig. 4 : Bar plot comparison of simulated and experimental piezometric heads. Each couple of bars represents a particular piezometer, with the first bar (red color) showing the numerical head $H(x, y)$ from the steady state coupled simulation, and the second bar (blue color) showing the piezometric head measured in situ. Most (but not all) of the 27 piezometers are located on the inner side (left bank) of the meander, which is in the top part of the simulation domain, approximately at $X \approx 1000 \mathrm{~m}$ and $Y \approx 5400 \mathrm{~m}$ in relative coordinates (see previous plane view figure).

\section{COASTAL HYDRODYNAMICS: CROSS-SHORE PROPAGATION OF WAVE-INDUCED OSCILLATIONS IN A BEACH WATER TABLE (WAVE CANAL)}

We focus in this section on a coupling problem in coastal hydrodynamics involving wave propagation through a sand beach.

We consider the case of a large wave canal containing a wave generator at one end, and a sloping beach at the other end, the beach being equipped with micro-piezometers. We focus on the cross-shore propagation of beach water table

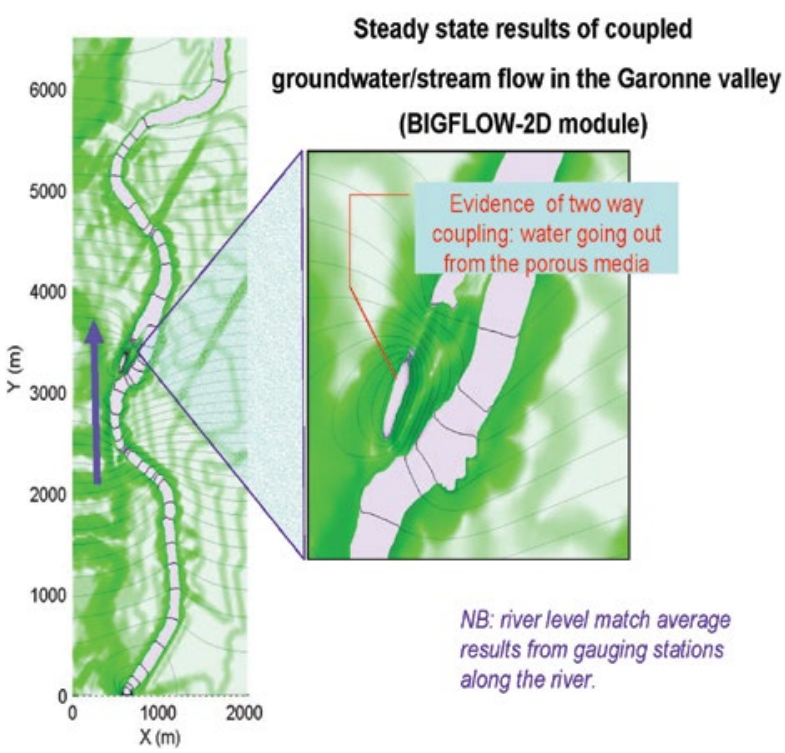

Fig. 3 : Plane view of the coupled stream/aquifer flow in the Garonne river valley, showing simulated water levels $H(x, y)$ both in the river and in the accompanying aquifer, for a mean seasonal steady state. Left: total simulation domain. Right: detailed view (zoom). The zoom shows the detailed piezometric curves around and inside an "islet" of sand and pebbles (relative coordinates $X \approx 700 \mathrm{~m}$, $Y \approx 3400 \mathrm{~m}$ ). The light blue / grayish color represents open water (surface water).

oscillations due to the incoming waves (sea swell waves arriving at the shore). This poses a particular coupling/ forcing problem at the beach entry. The open water oscillations in the sea need to be coupled with the water table oscillations in the sand beach, and their propagation in the cross-shore direction (i.e., along the axial direction of the canal). We focus on the numerical modeling problem, and we also compare model results with measured water levels from the micro-piezometers.

The proposed coupling / forcing method "weakly" couples the open water waves and the porous flow, but on the other hand, it is an "integrated" approach based on a single equational model and a single numerical code. This is achieved through some simplifying assumptions - to be explained below. The approach is appropriate only if the main objective is to study water table oscillations, rather than seawater hydrodynamics.

More precisely, the following equations describe the main features of the equational and numerical model (it is a generalized form of the Richards equation for variably saturated/ unsaturated flow with nonlinear, tensorial, spatially variable coefficients)...

(1) $\vec{q}=-\underline{\underline{K}}(h, \vec{x}) \vec{\nabla} H=-\underline{\underline{K}}(h, \vec{x}) \vec{\nabla}(h+z)$

(2) $\frac{\partial \theta_{e}(h, \vec{x})}{\partial t}=-\vec{\nabla} \bullet \vec{q} \Rightarrow \frac{\partial \theta_{e}(h, \vec{x})}{\partial t}=\vec{\nabla} \bullet\{\underline{\underline{K}}(h, \vec{x}) \vec{\nabla}(h+z)\}$

where: $H=h+z$ (if axis " $z$ " is vertical upwards),

$\vec{\nabla}$ is the $3 D$ gradient, and $\vec{\nabla} \bullet$ is the $3 D$ divergence operator. 
The Van Genuchten / Mualem model is used for the unsaturated constitutive relations expressing moisture $\theta(\mathrm{h})$ and conductivity $K(h)$ as a function of relative pressure $(h)^{6}$.

$$
\begin{aligned}
& \text { Saturation degree: } S(h) \equiv \frac{\theta(h)-\theta_{r}}{\theta_{s}-\theta_{r}}=\left[\frac{1}{1+(-\alpha h)^{n}}\right]^{m} ; \\
& \text { with } m=1-1 / n \\
& \text { Conductivity: } \frac{K(S)}{K_{S}}=S^{1 / 2}\left[1-\left(1-S^{1 / m}\right)^{m}\right]^{2} \Rightarrow \\
& \frac{K(h)}{K_{S}}=\frac{\left[1-(-\alpha h)^{n-1}\left[1+(-\alpha h)^{n}\right]^{-m}\right]^{2}}{\left[1+(-\alpha h)^{n}\right]^{m / 2}}
\end{aligned}
$$

In equations (IV.1) \& (IV.2), $\vec{q}$ is the flux density vector or "Darcy velocity" $(\mathrm{m} / \mathrm{s}) ; \theta$ is the volumetric water content $\left(\mathrm{m}^{3} / \mathrm{m}^{3}\right)$; " $\mathrm{h}$ " is relative pore pressure defined by $\mathrm{h}=\left(\mathrm{p}-\mathrm{p}_{\mathrm{ATM}}\right) / \mathrm{\rho g}$; " $\mathrm{H}$ " is total hydraulic head $(\mathrm{H}=\mathrm{h}+\mathrm{z}$ if " $\mathrm{z}$ " is vertical upwards); $\mathrm{K}$ is the unsaturated hydraulic conductivity $(\mathrm{m} / \mathrm{s}) ; \mathrm{K}_{\mathrm{S}}$ is the saturated conductivity $(\mathrm{m} / \mathrm{s})$; and $\theta_{\mathrm{S}}$ is the saturated water content (or porosity). The constitutive relation $\theta(\mathrm{h})$ is called water retention curve, and $\mathrm{K}(\mathrm{h})$ is the unsaturated conductivity curve. These curves express the pressure dependence of $\theta$ and $\mathrm{K}$ in the unsaturated case, where $\mathrm{h} \leq 0$. On the other hand, for positive pressures $\mathrm{h} \geq 0$, the medium is saturated, and we have $\theta(\mathrm{h})=\theta_{\mathrm{s}}$ and $\mathrm{K}(\mathrm{h})=\mathrm{K}_{\mathrm{S}}, \forall \mathrm{h} \geq 0$.

In equations (IV.1), the 1rst equation is the law of Darcy (also known as Darcy-Buckingham for variably saturated media), and the 2nd equation is mass conservation (assuming incompressible water and porous matrix).

The mass conservation equation is the final governing equation, in our approach, for modeling $3 \mathrm{D}$ water flow in variably saturated / unsaturated porous media. It takes the form of a mixed variable nonlinear PDE, expressed in terms of moisture and pressure. A volumetric source term can also be added. In saturated zones, water content equals porosity $\theta_{\mathrm{s}}$. In unsaturated zones, water content $\theta(\mathbf{x}, \mathbf{t})$ is calculated as a function of pressure $h(\mathbf{x}, t)$ from the $\theta(h)$ curve (1rst equation in eqs. IV.2). The Darcy flux $\mathbf{q}(\mathbf{x}, t)$ is then calculated from pressure gradients using the Darcy equation (1rst equation in eqs. IV.1). It is important to note that the mixed formulation in terms of moisture and pressure makes our model applicable to partially saturated as well as unsaturated domains. In fact, the transient PDE can behave as a parabolic, elliptic, or even hyperbolic PDE in different flow regions, depending on the variably saturated flow regime (for more, see Ababou 2008 and references therein).

For the wave canal / sand beach simulation, the computational domain is a rectangular vertical cross-section $(\mathrm{x}, \mathrm{z})$, comprising the sloping sand beach and a region of open seawater (at left). The domain size is $\mathrm{Lx}=10 \mathrm{~m} \& \mathrm{Lz}=0.8 \mathrm{~m}$. The numerical mesh size is $\Delta \mathrm{x}=0.02 \mathrm{~m} \& \Delta \mathrm{z}=0.02 \mathrm{~m}$. The beach slope is $1 / 15$. The time scale of the simulation is $\mathrm{t}_{\mathrm{MAX}}=2450 \mathrm{~s}$ (same as the experimental wave generation sequence labeled "Run 14"). The initial condition (IC) and boundary conditions (BC) used in the simulation are:

IC $(\mathrm{t}=0)$ : hydrostatic pressure distribution $\mathrm{h}(\mathrm{x}, \mathrm{z})=$ Ho-z $=0.17 \mathrm{~m}-\mathrm{z}$

6. For simplicity here, we assume $\mathrm{K}(\mathrm{h})$ is scalar. We will not consider the possible anisotropic nature of the tensorial unsaturated conductivity function $\mathrm{K}(\mathrm{h})$, although we have used this feature in some simulation tests.
$\mathrm{BC}$ at left vertical face $(\mathrm{x}=0): \mathrm{h}(0, \mathrm{z}, \mathrm{t})=$ $\mathrm{H}_{1}(\mathrm{t})-2.30 \mathrm{~m}-\mathrm{z}$

$\mathrm{BC}$ at right vertical face $(\mathrm{x}=\mathrm{Lx})$ : null horizontal flux $\mathrm{q}_{\mathrm{x}}=0$

$\mathrm{BC}$ at the bottom $(\mathrm{z}=0)$ : zero vertical flux $\mathrm{q}_{\mathrm{z}}=0$

BC on top $(z=L z)$ : zero vertical flux $q_{z}=0$

where $\mathrm{h}(\mathrm{x}, \mathrm{z}, \mathrm{t})$ is the water pressure in the micro and macro porous media, and $H_{1}(t)$ is the water level (hydraulic head $\mathrm{H}$ ) measured at piezometer No.1 in seawater, close to the beach.

Note that the seawater oscillations are forced via the boundary condition on the left vertical face. The sloping beach/sea interface is treated as an internal surface rather than a boundary. In other words, the interface condition is obtained indirectly by forcing a quasi-static but oscillatory vertical pressure profile (corresponding to an oscillatory water level $\mathrm{H}_{1}(\mathrm{t})$ ) in the seawater (macro-porous medium) at some distance from the inclined sandy beach. This type of indirect forcing is an essential coupling feature of the present model.

The water content curves and hydraulic conductivity curves of the composite medium constituting the simulation domain, are shown further below in Fig. $8(a, b)$. The simulation domain is made up of (1) a classical microporous medium (the sand beach), and (2) a non-classical macro-porous medium (open seawater). Both are treated as variably saturated/unsaturated porous media. The numerical parameter values are:

Micro-porous (sand beach): $K s=0.005 \mathrm{~m} / \mathrm{s} ; \theta s=0.38 \mathrm{~m}^{3} / \mathrm{m}^{3}$; $\alpha=5.0 \mathrm{~m}^{-1} ; n=1.5$

Macro-porous (open water): $K s=50.0 \mathrm{~m} / \mathrm{s} ; \theta s=1.00 \mathrm{~m}^{3} / \mathrm{m}^{3}$; $\alpha=100.0 \mathrm{~m}^{-1} ; n=3.0$

Note that the porosity of the macro-porous medium is taken equal to $1.0 \mathrm{~m}^{3} / \mathrm{m}^{3}(100 \%) \ldots$ as it should for open water. The saturated conductivity of the macro-porous medium (open water) is 10000 larger than that of the micro-porous medium (ideally, this ratio should be infinite). The capillary length $\lambda \approx 1 / \alpha$ is 20 times larger for the micro-porous medium compared to the macro-porous medium (ideally, this ratio should also be infinite). Finally, concerning exponent " $\mathrm{n}$ ", we have $\mathrm{n}_{\text {маско }}>>1$ for the macro-porous medium ( $\mathrm{n}_{\text {масво }}$ should be much larger than $\mathrm{n}_{\text {мгско }}$, and ideally, $\mathrm{n}_{\text {маско }}$ should go to infinity).

In the experimental study, we used a $70 \mathrm{~m}$ long experimental wave canal hosted in the HYDRALAB research laboratory (Barcelona, Spain). The wave canal was used experimentally, by us, in the framework of European R\&D project "SANDS". The sand beach is located at one end of the canal, opposite to the wave generator, and it is equipped with micro-piozemeters aimed at measuring water levels $\mathrm{H}(\mathrm{x}, \mathrm{t})$ at various positions, in the wave canal itself, in the swash zone, and further in-land (monitoring of the beach water table). Note: " $x$ " is the longitudinal axis of the canal, oriented across the shore, and directed "in-land".

Let us focus in particular on how to account for coupling/forcing between the incident water waves arriving at the inclined sand beach, and the oscillating water table in the beach subsurface. The general idea is to use a simplified coupling model such that the micro-piezometers located at the beach entry can be used as forcing. With this general idea as a guideline, the main challenge is to design a dynamic flow model that takes into account the existence of two adjacent water flow zones: (i) an open water "medium" 
(the shallow sea near the swash zone), and (ii) a porous medium consisting of the inclined sand beach. The model should take into account the inclined geometry of the beach as well some "coupling", so that the seawater oscillations do propagate through the beach groundwater in-land.

The coupling method used to achieve these goals is again a strongly "implicit" or "internal" coupling, using a single equational model and a single computer code (BIGFLOW 3D), properly generalized. In particular (among other generalizations), the Darcy-Forchheimer model is used for the head loss law, with total pressure gradient proportional to a linear combination of two velocity terms: the velocity $\mathbf{V}$ itself (Darcy), and a "quadratic" velocity term $|\mathbf{V}| \mathbf{V}$ (Forchheimer). At the same time, the governing equation retains the features of the mixed form of Richards equation for saturated/unsaturated flow.

This equational model is applied to any spatial location $(\mathrm{x}, \mathrm{y}, \mathrm{z})$ within the composite "sea/beach" medium. The porous medium (sand beach) is represented by 3D porous cells. Each porous cell can be in a saturated or unsaturated state. The seawater zone is represented artificially with $3 \mathrm{D}$ macro-porous cells having $100 \%$ porosity, very large permeability, and a few other special features such as a very steep water retention curve (the water content $v s$. capillary pressure relationship approaches a Heaviside function). The porous and macro-porous cells are assembled in space according to the sloping geometry of the sand beach.

In this way, open water oscillations due to the incoming waves from the sea, can interact with the sloping beach and can penetrate and propagate through the porous sand, while conserving mass in the process. This can be implemented either in $3 \mathrm{D},(\mathrm{x}, \mathrm{y}, \mathrm{z})$, or in vertical cross-section,

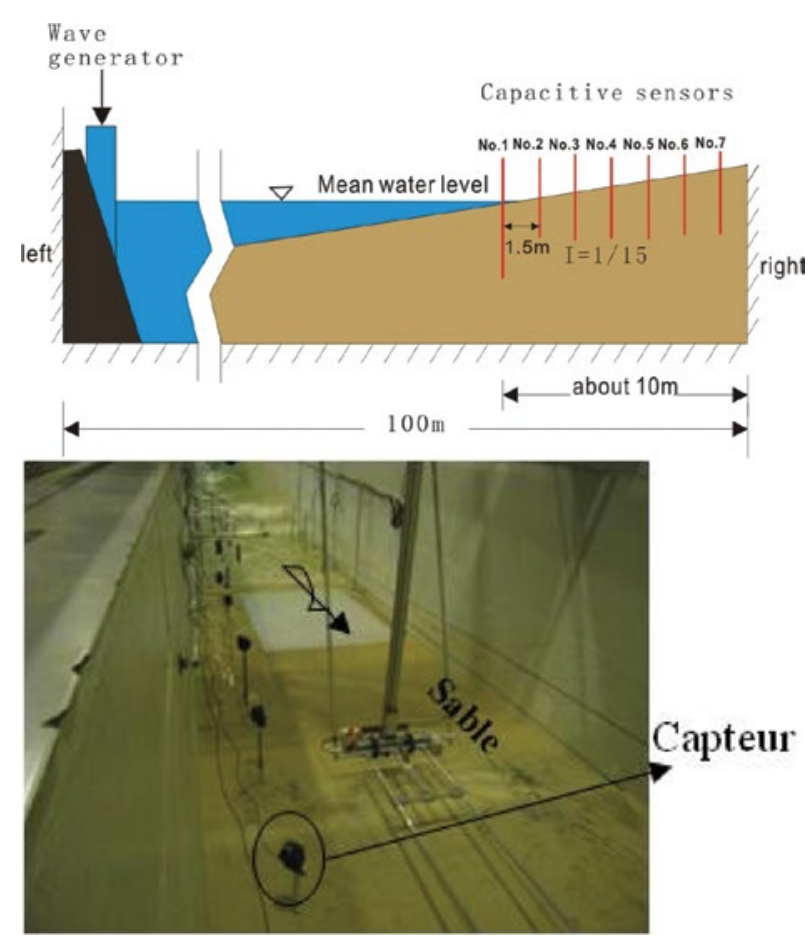

Fig. 5(a): Above: schematic view of the beach at the end of the wave canal (axial vertical cross-section) showing the capacitive water level sensors (micro-piezometers). Sensor $N^{\circ} 1$ is located in the entry zone (open water). Below: photograph of the beach and micro-piezometers. $(\mathrm{x}, \mathrm{z})$. For our particular wave canal application, we neglect transverse water flow (y) with respect to axial and vertical water movements $(\mathrm{x}, \mathrm{z})$, and we implement the 3D coupled saturated/unsaturated porous/macro-porous model in vertical cross-section $(\mathrm{x}, \mathrm{z})$.

The geometry of this coastal hydraulics problem (wave canal, sloping beach, water table) and some of the numerical modeling results, are displayed in Fig. 5, Fig. 6, and Fig. $7(a, b)$. The results are far from perfect, but they are still adequate given our objectives, i.e. (namely), to study the dynamics of the beach water table in the wave canal (see for instance measured vs. simulated water table levels in Fig. 6). There are more details and comments in the figure captions (Fig. 5, 6, 7). The reader is also referred to the final section on discussion and conclusions. Finally, concerning other aspects on the experimental set up, the numerical simulations, and the statistical/spectral analyses of water level fluctuations $\mathrm{H}(\mathrm{x}, \mathrm{t})$, see also Wang (2010), Ababou et al. (2010), and Wang et al. (2010, 2012).

\section{COASTAL HYDRODYNAMICS: TIDAL OSCILLATIONS IN A BEACH COLUMN (IMFT "TIDE MACHINE" EXPERIMENT AND MODELING)}

We consider in this section a somewhat different problem of coastal hydrodynamics: the effects of low frequency oscillations, or tidal oscillations, in a vertical column of sand beach, based on IMFT's "Tide Machine" experiment and modeling concepts. We present a synthetic account of the
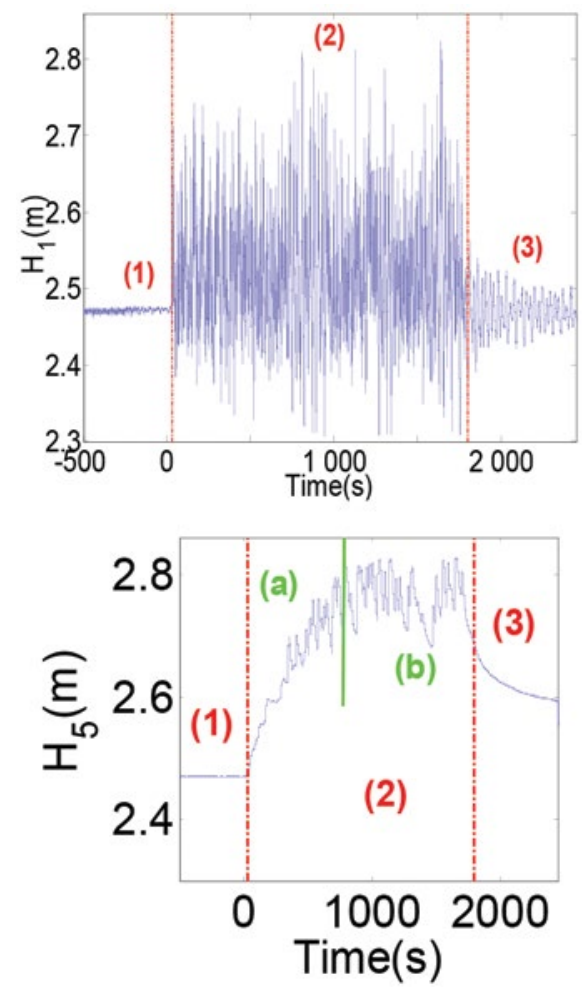

Fig. 5 (b): Above: signal H1(t) recorded at the entry zone (sensor $N^{\circ} 1$ ) during a $1 / 2 \mathrm{~h}$ cycle of wave generation (from $t=-500 \mathrm{~s}$ to $t=+2000 \mathrm{~s}$ ). Below: signal H5(t) recorded at sensor $N^{\circ} 5$ during the same wave cycle. 

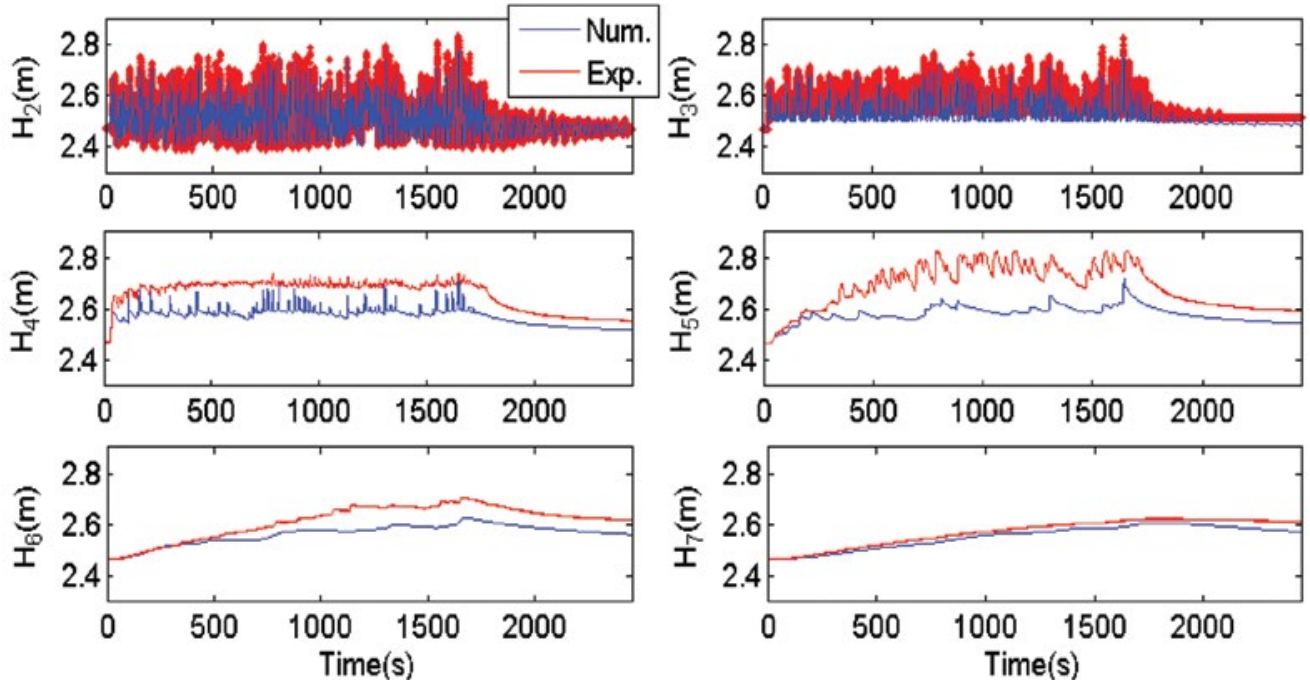

Fig. 6: Comparison of piezometric signals $\mathrm{H}_{\mathrm{i}}(\mathrm{t})$, numerical (blue) vs. experimental (red). Each graph shows the temporal evolution and the fluctuations of the beach water table level $\mathrm{H}\left(\mathrm{x}_{\mathrm{i}}, \mathrm{t}\right)$, at a given cross-shore location $\mathrm{x}_{\mathrm{i}}$ for six locations $\left(\mathrm{x}_{2}\right.$ is closer to the sea and $\mathrm{x}_{7}$ further away from the sea).

(a)
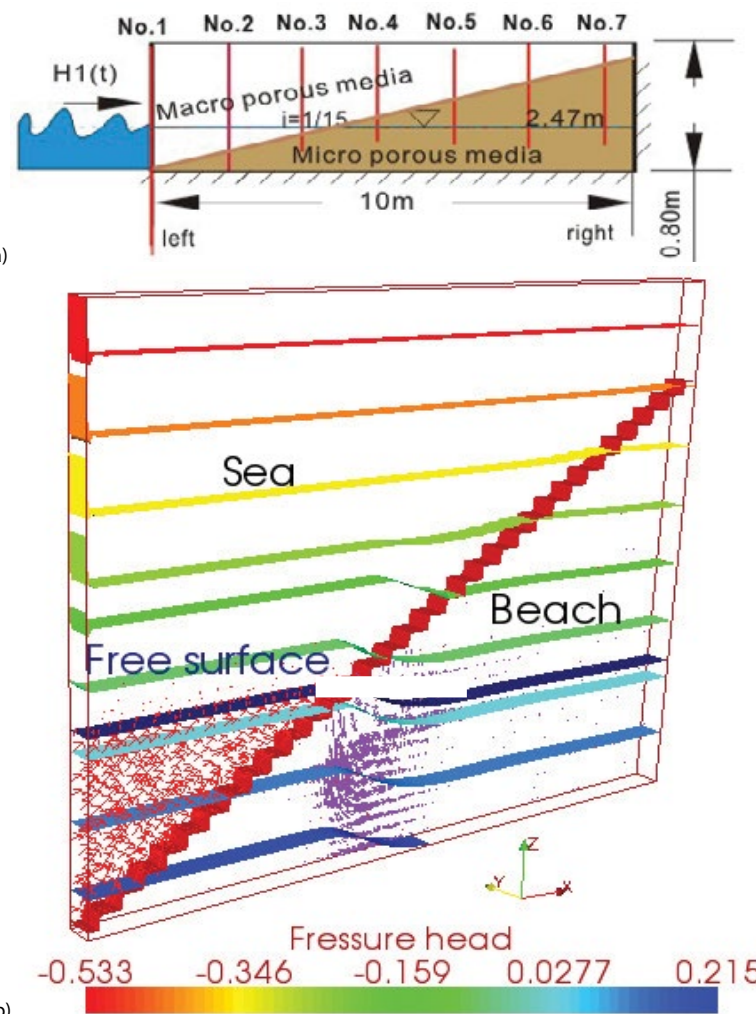

(b)

Fig. 7 (a,b): (a): Schematic representation of a vertical transverse section $(x, z)$, perpendicular to the sea shore, depicting the coupled simulation of forced oscillations in the open water / sloping sand beach domain. (b): Instantaneous iso-values of relative water pressure head $h(x, z, t)$ $[-0.533 \mathrm{~m},+0.215 \mathrm{~m}]$, and velocity vectors, in the wave entry zone and in the sand beach. In this graphic, the velocity scale is amplified by a factor $\sim 60$ in the porous medium $\left(V_{\text {DARCY }} \times 20, V_{\text {OPEN WATER }} \times 0.3\right)$.
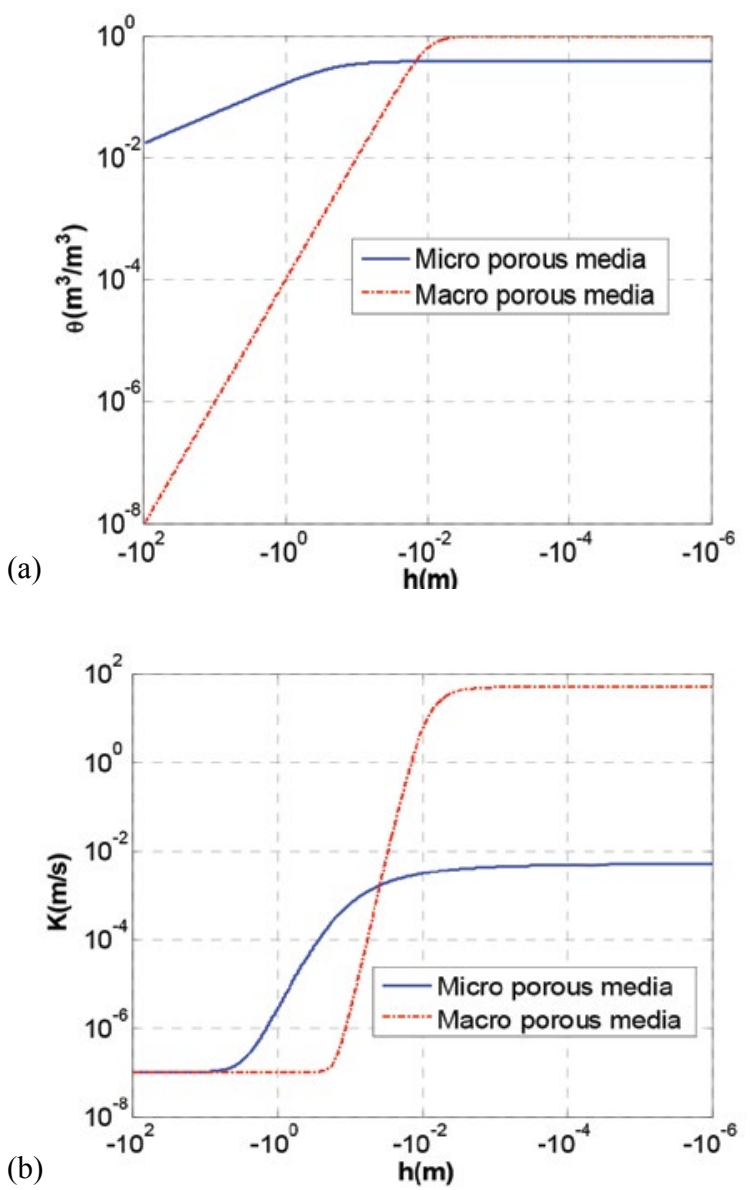

Fig. 8 (a,b): (a): Log-Log plot of volumetric water content curve $\theta(h)$ for the micro-porous medium (sand beach) and the macro-porous medium (seawater). The steepest curve is for the macro-porous medium. (b): Log-Log plot of unsaturated hydraulic conductivity curve $K(h)$ for the micro-porous medium (sand beach) and the macro-porous medium (seawater). The steepest curve is for the macro-porous medium. 
methods and results from this on-going work (Alastal et al. 2010, 2011, and Alastal 2012). In particular, we present here in some detail the experimental Tide Machine apparatus. Our analyses focus on the behavior of the beach column under forced "tidal" oscillations of pressure imposed at the basis of the column. The response of the partially saturated column is analyzed in terms of water table fluctuations, with a focus on unsaturated flow effects in the capillary zone above the water table (one of the main goals of this study).

Specifically, let us consider a partially saturated/ unsaturated vertical porous column under dynamic conditions of oscillating positive pressure at some depth, representing the effects of sea tides in the beach. This effect is simulated, specifically, by imposing an oscillatory (sinusoïdal) "entry" pressure head at the bottom face $(\mathrm{z}=0)$ of a partially saturated porous column. This is expressed as follows:

$$
h(z=0, t)=h_{0}(t)=\overline{h_{0}}+A_{0} \sin \left(\omega_{0} t\right)
$$

where:

- $\overline{h_{0}}$ is the positive time-averaged value of the entry pressure head sinusoidal signal, chosen to coincide with the initial hydrostatic level in the column;

- $A_{0}$ is the amplitude of the oscillating entry pressure head signal;

- $\omega_{0}=2 \pi / T_{P}$ is the angular frequency of the oscillating entry pressure head; and

- $T_{P}$ is the period of the oscillating entry pressure head signal.

The motivation for this type of tidal forcing is explained in Fig. 9 (left) showing a schematic view of the beach system, and of the position of the vertical soil column with respect to the shore. As indicated in this figure, it is thought that the vertical soil column is representative of the effect of tides if the column is located beyond the swash zone, i.e., sufficiently away from the swash zone (further inland).

In addition, the conceptual configuration of the vertical soil column is explained in Fig. 9 (right) from the point of view of porous media hydrodynamics. Note the existence of two zones: the saturated zone at bottom (where relative pore pressure " $\mathrm{h}$ " is positive), the unsaturated zone above (where relative pore pressure " $h$ " is negative), and the mobile free surface or water table $(h=0)$ separating the two zones.

Experimentally a harmonically oscillating driving head can be generated by a "tide machine" connected to the bottom of the column. This concept is illustrated by the schematic reproduced in Fig. 10, which describes an actual instrumented soil column and the associated "tide machine".

In addition, Fig. 11 shows a different, simplified schematic view of the rotating overflow tank and its connections to the soil column and to the storage tank.

Note that the regulation role played by the storage tank is necessary. The flow rate in and out of the partially saturated soil column is not known in advance. Indeed, the flow rate at the base of the column does not depend only on the periodic pressure forcing imposed by the tide machine: it depends also on the nonlinear response of the partially saturated soil column.

Fig. 12 shows a series of photographs depicting different parts of the experimental set up in the laboratory (see caption).

Finally, Fig. 13 \& Fig. 14 show two direct results from the tide machine experiments, in terms of measured pressure heads and hydraulic heads in the sand column. Fig. 13 shows the temporal evolution of relative pressure heads " $h$ " at different heights " $\mathrm{z}$ " in the column (for a given tidal period Tp), while Fig. 14 displays vertical profiles of total head " $\mathrm{H}$ ", defined as $\mathrm{H}=\mathrm{h}+\mathrm{z}$, at different times, for two different tidal periods. The results of Figs. $13 \& 14$ will be commented further in the final conclusions and discussion section, along with discussion of other results and observations from the tide machine study.

It is emphasized that these results are just a representative subset, extracted from a more comprehensive set of both numerical and laboratory experiments. Tide machine experiments were conducted, in the laboratory, for a few tidal frequencies, on a "short" and a "long" soil column, respectively. The results have been analyzed and compared with quasi-analytical and numerical models, after calibration of unsaturated/saturated properties of the soils used in the columns (see details in Alastal 2012). Early experimental results from these tidal soil column experiments were also partially reported in Alastal, Ababou, Astruc (2011). Futhermore, the tidal sand column experiments were also numerically
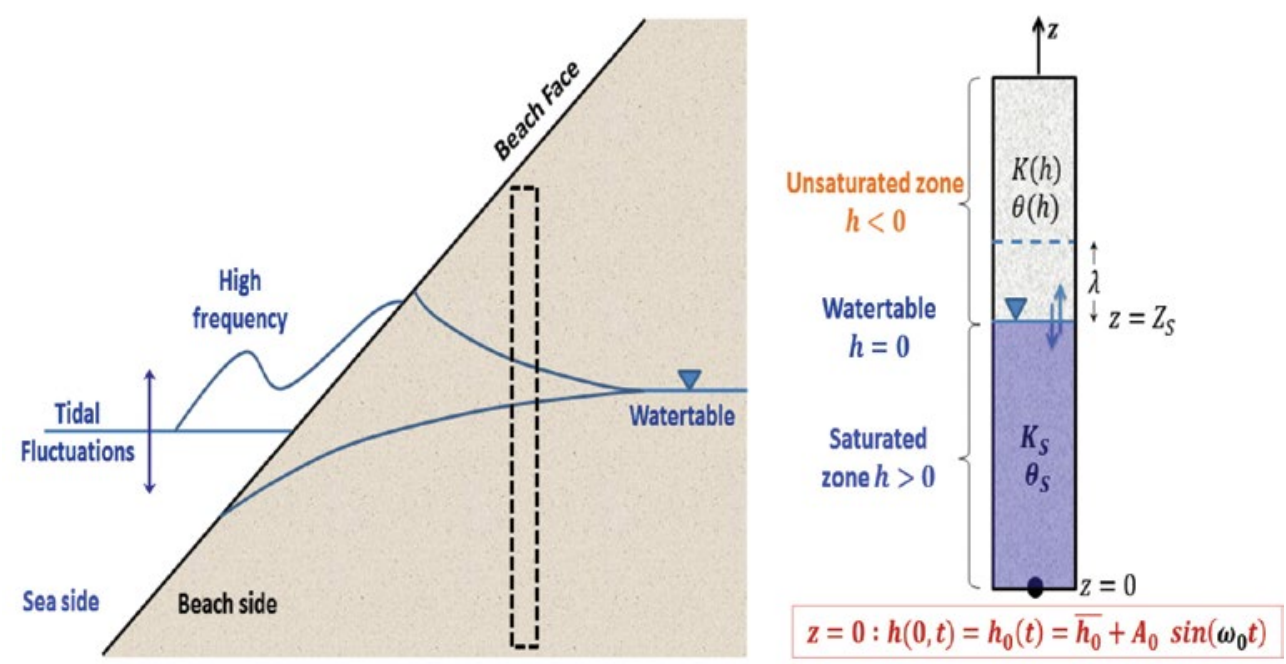

Fig. 9: Left: schematic depiction of the beach system, and the position of the vertical soil column with respect to the shore (the column is located beyond the swash zone, slightly further inland). Right: schematic configuration and hydrodynamic properties of the partially saturated, vertical soil column under tidal forcing at bottom. 

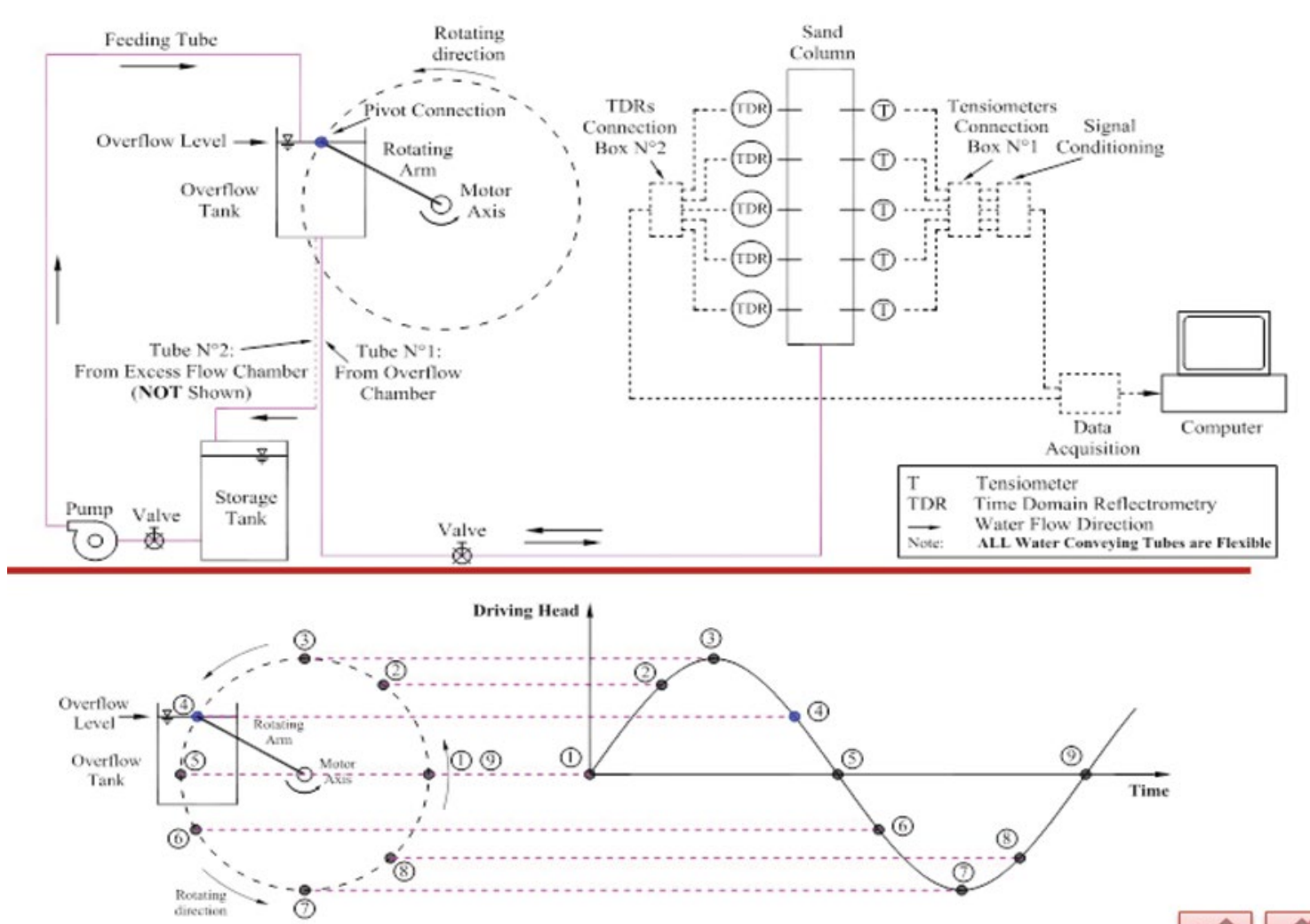

Fig. 10: Schematic diagram of the experimental "tide machine", soil column, and measurement system including suction cup micro-tensiometers, and TDR moisture probes (Time Domain Reflectometry). The top left schematic shows the rotating overflow tank and its engine (tide machine); the top right schematic shows the soil column equipped with instrumentation. The schematic at bottom shows how the circular path of the overflow tank provides a sinusoidal function of time for the driving head imposed at the bottom of the soil column. (NB: this schematic corresponds to the first series of tidal experiments, labeled "short column" experiments).

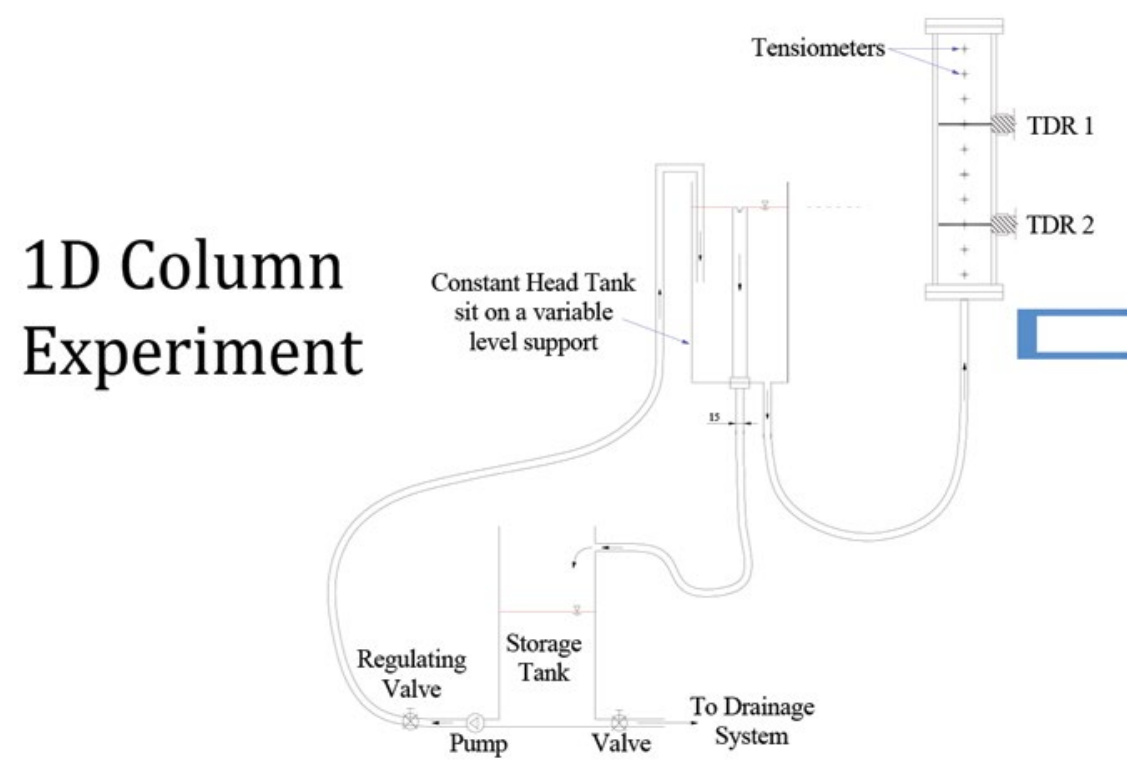

Fig. 11: Simplified schematic showing the mobile overflow tank and its connections with the storage tank (below) and with the soil column (top right). The tide machine is not shown.

modeled using the variably saturated Richards equation and the Van Genuchten/Mualem relations (see eqs. III.1 \& III.2 earlier). Work is still ongoing towards physical interpretation and generalization of some these modeling results. See also discussion and conclusions in Section VI.
The tide machine experiments and their analyses were conducted at the Institut de Mécanique des Fluides de Toulouse, in a collaborative endeavor involving two research groups, focused on porous media (GEMP) and on environmental turbulence \& waves (OTE). 


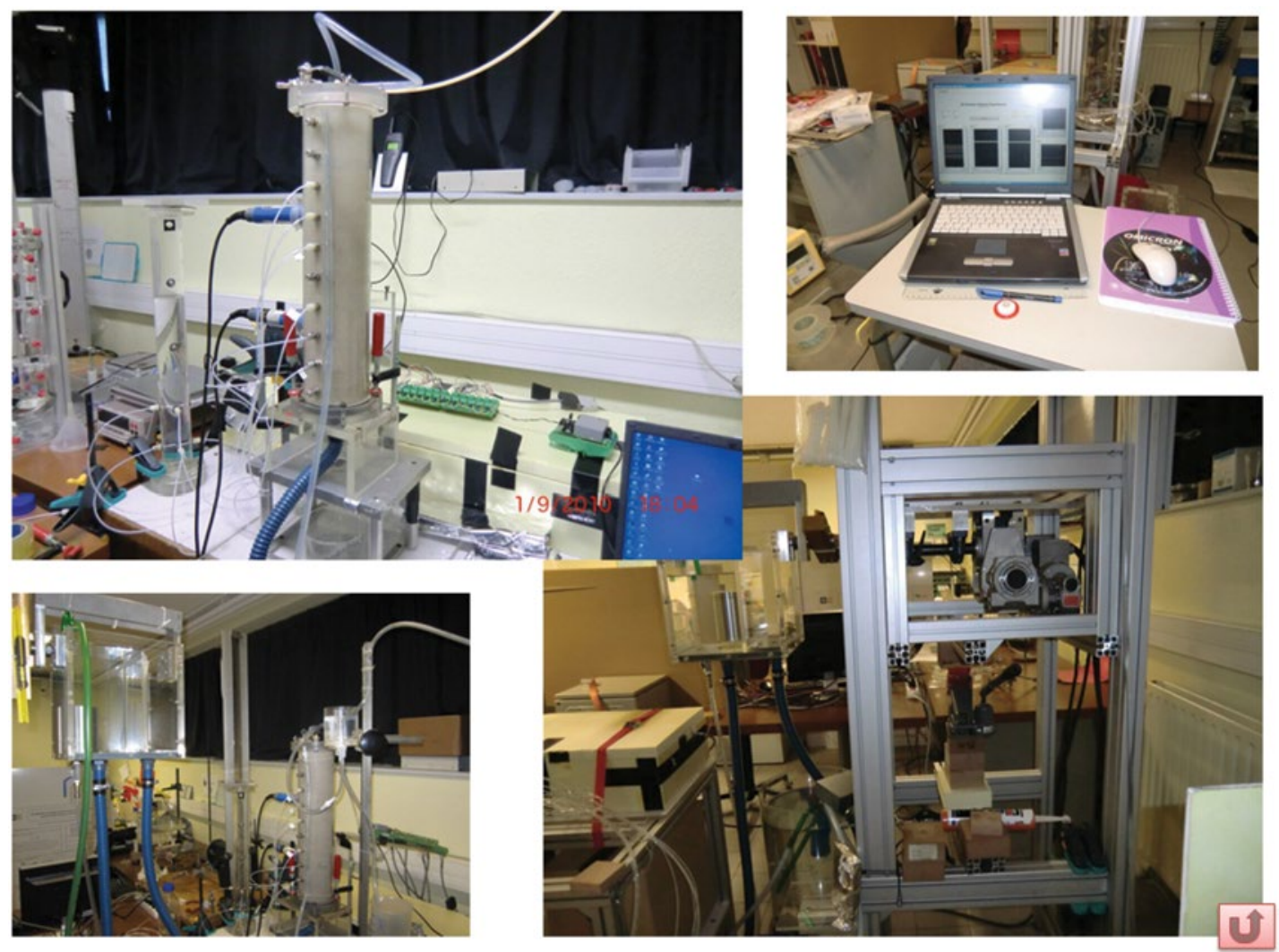

Fig. 12: Photographs showing different views of the short column series of experiments. Top left: soil column equipped with pressure/suction tensiometers, and two TDR moisture probes. Bottom left: mobile overflow tank in the foreground, next to the soil column in the background (the two are connected). Top right: Personal Computer connected to data acquisition interfaces (not shown); the LABVIEW software was used for monitoring and processing the tensiometric signals as well as the room temperature signal for calibration purposes. Bottom right: this photograph shows the metal structure supporting the tide machine, its electric engine, and rotating arm...
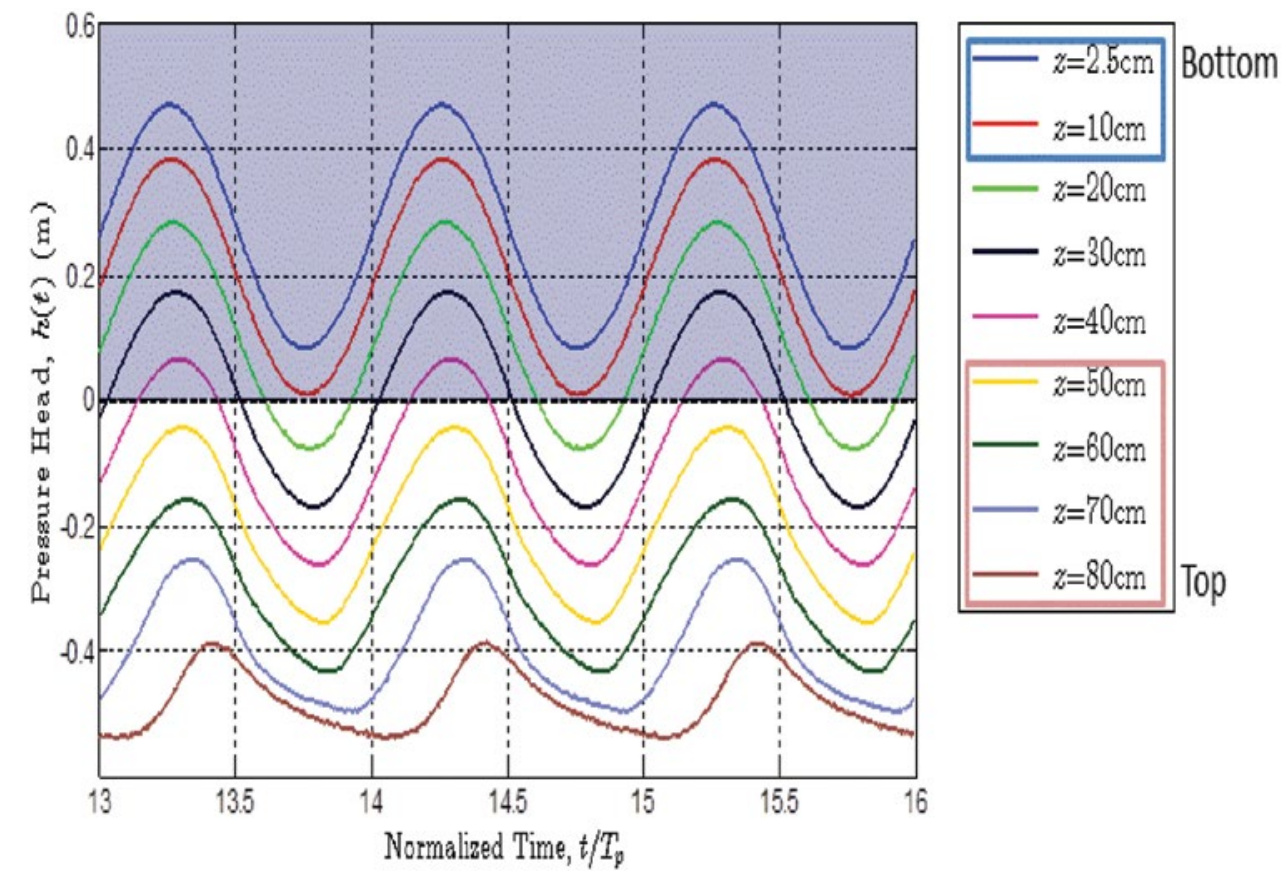

Fig. 13: Temporal evolutions of measured pressure head h(t) during 3 tidal cycles, at 9 different heights in the "SilicaSand" column (tensiometers at heights $z=2.5 \mathrm{~cm}, 10 \mathrm{~cm}, 20 \mathrm{~cm}, 30 \mathrm{~cm}, 40 \mathrm{~cm}, 50 \mathrm{~cm}, 60 \mathrm{~cm}, 70 \mathrm{~cm}, 80 \mathrm{~cm}$ ). For this tide machine experiment, the input parameters are: the forcing amplitude $A_{0}=0.20 \mathrm{~m}$, the mean forcing pressure (static level) $\overline{h_{0}}=0.30 \mathrm{~m}$, and the forcing period $T_{p}=110 \mathrm{mn}$. In this $(h, t)$ graphic, the grey shadowed zone above indicates positive pressures, $h(t) \geq 0$ (saturated soil). It can be seen that the bottom part of the column $z \leq 15 \mathrm{~cm}$ is in a state of saturation at all times, and the top part $z \geq 45 \mathrm{~cm}$ is unsaturated at all times. The intermediate zone $(15 \mathrm{~cm} \leq z \leq 45 \mathrm{~cm})$ is intermittently saturated / de-saturated during any tidal cycle. 

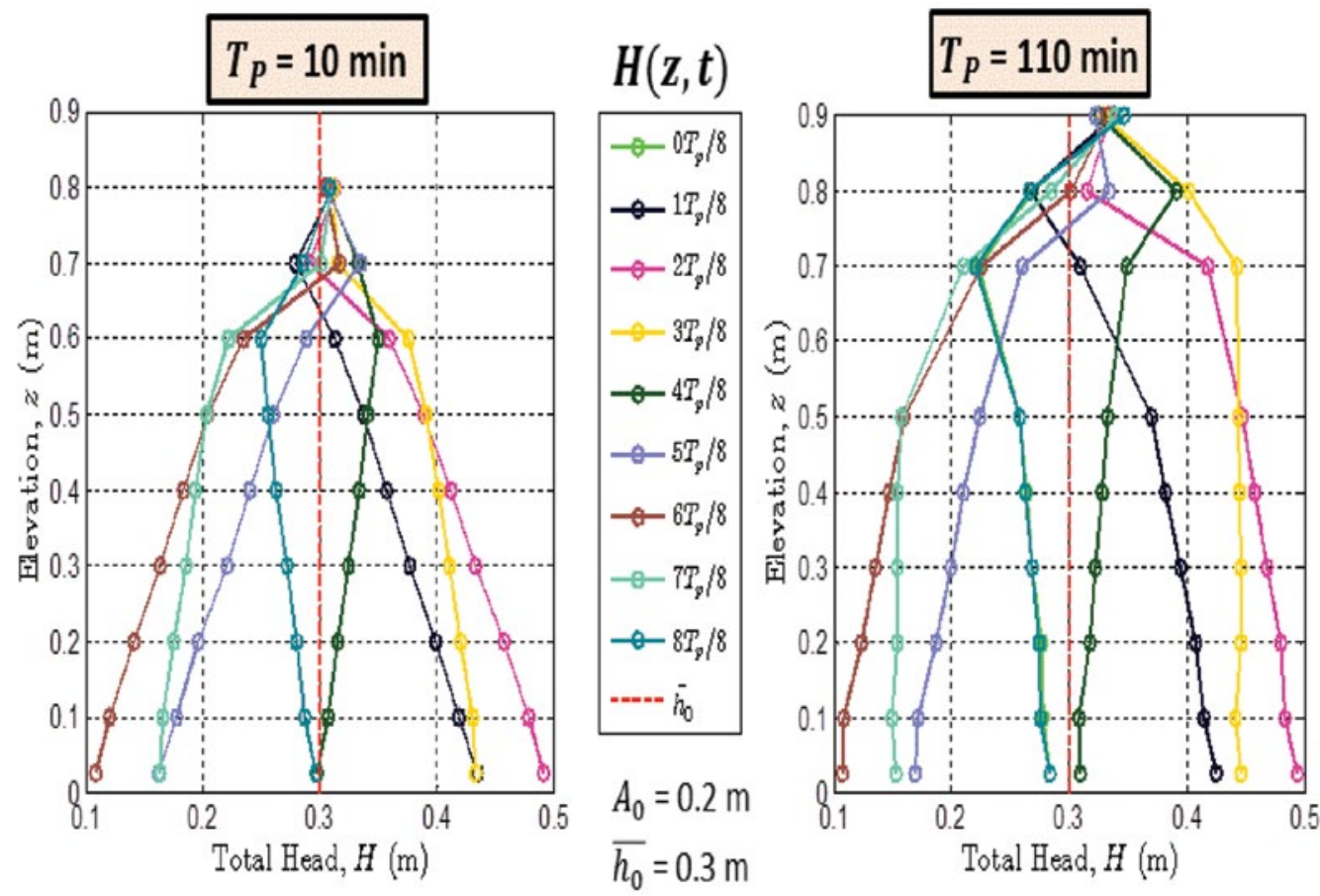

Fig. 14: Vertical profiles of measured hydraulic head $H(z)$, at different times " $t$ " during a single tidal cycle ( $t=0$ to $t=T p)$, for the "SilicaSand" column (tide machine / long column experiment). Note: only the lower part of the column is shown here, from $z=0$ to $z=90 \mathrm{~cm}$. The results are presented for two "tidal" periods: $T p=10 \mathrm{mn}$ (left), and $\mathrm{Tp}=110 \mathrm{mn}$ (right). In both cases, the sinusoïdal pressure head imposed at the bottom $(z=0)$ has an amplitude Ao= $20 \mathrm{~cm}$, and a mean "static" value ho=30 cm. Total head profiles, defined as $H(z, t)=h(z, t)+z$, were constructed from tensiometric measurements of pressure $h(z, t)$. Each circle symbol "o" corresponds to a tensiometric measurement $h(z, t)$, from which $H(z, t)$ was obtained. On both plots, the 8 colored curves are the instantaneous profiles collected every $8^{\text {th }}$ of a period during one tidal cycle: $t=\{0 \times T p / 8 ; 1 \times T p / 8 ; 2 T p / 8 ; \ldots$; $7 \times T p / 8 ; 8 T p / 8\}$. The static head profile is the vertical dashed line $H(z)=h o=0.30 \mathrm{~m}$. Head profiles are all shown as $(z, H)$ curves, with " $H$ " as abscissa and " $z$ " as ordinate (axis " $z$ " is vertical upward).

\section{CONCLUSIONS AND DISCUSSION}

We have presented in this paper several numerical and experimental studies of environmental flow problems where, to various degrees, the mathematical and numerical modeling of the problem involves some assumptions on how to "couple" or to "force" the flow processes occurring in different subdomains: stream / aquifer; wave canal / porous beach; tidal oscillations / vertical flow oscillations in a saturated / unsaturated soil column (with a fluctuating water table separating the two zones).

The stream-aquifer flow problem in an alluvial valley was treated in Section III with a "strongly" coupled approach (a direct and implicit "equational" coupling), based on the hypothesis of pressure continuity at the aquifer/streambed interface. This strongly coupled approach is implemented based on a single vertically integrated flow model, both in the river and in the accompanying aquifer. Some of the results shown here indicate that this type of model is able to capture, for instance, the effect of river flow on aquifer flow (the faster flow in the river appears to generate a visible "wake" in the aquifer flow). The geometry of the river, with its meanders, has also some visible effects on subsurface flow. There is generally a satisfactory goodness-of-fit between the modeled piezometric levels and the measured ones. Finally, a detailed view shows how the local surface/subsurface flow pattern is perturbed by the presence of a pebble islet in the river.

It should be noted that the same vertical averaging / strong coupling approach has been extended to "3-way coupling" of
(1) surface water, (2) subsurface freshwater, and (3) subsurface seawater, for instance in a coastal estuary. For the interested reader, a simplified synthetic example of 3-way flow coupling in a meandering estuary is presented in Al Bitar \& Ababou (2006), in Ababou \& Al-Bitar (2008), and with more details, in Al-Bitar (2007, in french).

In this paper, we also considered other coupling issues that arise in coastal and beach hydrodynamics. A modeling strategy was needed for transmitting oscillations from seawater to the adjacent porous body (the beach). Once the model is established, the goal is to analyze the hydraulic response of the beach forced by seawater oscillations or waves. Because the beach response was our main focus, the seawater forcing was simplified (for other applications, our simplifying assumptions would have to be revised). However, it is possible that our present simplified approach could be applied not only to a sand beach and its interactions with the sea, but also to other similar problems in various areas (porous dikes in harbors, earth dams, etc.).

Thus, we presented in Section $I V$ the case of a large wave canal containing a wave generator at one end, and a sloping sand beach at the other end equipped with micro-piezometers. The objective was to study the cross-shore propagation of beach water table oscillations due to the incoming waves (sea swell waves arriving at the shore). This posed a particular coupling/forcing problem at the beach entry. This was achieved by a "weak" but "integrated" coupling approach, based on a single equational model and a single 
finite volume code based on generalized saturated/unsaturated Darcy-Forchheimer, with porous cells in the beach and macro-porous cells in the adjacent sea water, considered in vertical cross-section $(\mathrm{x}, \mathrm{z})$. The flow equation is not vertically integrated, but other simplifying assumptions are made.

Essentially, this coupling ensures mass conservation across the sloping sea/beach interface, as well as beach/sea feed-backs, but the flow system in the sea itself remains quasi-static far away from the beach (the sea level far from the beach is oscillatory but quasi-horizontal). As already mentioned, this approach seems appropriate only if the main objective is to study water table oscillations, rather than seawater hydrodynamics.

We have presented some of the numerical modeling results in vertical cross-section (Fig. 6), and we also compared model results with micro-piezometric measurements of water levels $\mathrm{H}(\mathrm{x}, \mathrm{t})$ at different distances from the shore (Fig. 7(b)).

From Fig. 6, it can be seen that the temporal evolution of modeled water levels $\mathrm{H}\left(\mathrm{x}_{\mathrm{i}}, \mathrm{t}\right)$ matches qualitatively, but not precisely, the structure of piezometric measurements. The fluctuation structures and the long term trends are similar for all positions. However, there is a very close match only for the last piezometric level $\mathrm{H} 7(\mathrm{t})$, located at position $\mathrm{x} 7$ furthest away from the shore. As an additional note, it should be emphasized that other interpretations have been developed based on temporal cross-correlation structures and Fourier spectra of $\mathrm{H}(\mathrm{t})$ at various positions cross-shorewise (Wang et al.). Thus, time delays and wave celerities were estimated using along the cross-shore direction. These analyses confirmed that modeled \& measured piezometric signals have similar structures and responses. Also, in both the modeled and measured signals $\mathrm{H}(\mathrm{t})$, the lowest frequencies of water level fluctuations propagate more deeply in the sand beach (across shore) than higher frequencies.

Furthermore, Fig. 7(b) confirms that the coupled model simulates flow in both seawater + beach, clearly taking into account the sloping geometry of the beach in $(\mathrm{x}, \mathrm{z})$ crosssection. This is made possible (at the price of simplification of seawater dynamics) by encompassing in a single domain two distinct material subdomains (macro-porous \& micro-porous) separated by the sloping beach interface. This method can be extended to any other interface geometry in 3D (allowing overhanging interfaces as well). Overall, the results indicate that the method permits some kind of two-way coupling between seawater and the porous inclined beach, although, as stated earlier, the seawater flow itself is oversimplified.

Finally, we presented in Section $V$ an experimental and numerical analyzis of "tidal" oscillations of vertical flow (flux, pressure, moisture) in a partially saturated / unsaturated column of beach sand, with a fluctuating water table separating the two zones. This problem involves two aspects. Firstly, for the sea/beach system, the vertical oscillations in the beach column were "forced" by imposing harmonic oscillations of positive pore pressure at some depth, in the saturated part of the column. Secondly, the physics of the flow problem involves a coupling between saturated \& unsaturated domains within the column. This is realized as an "internal" coupling where the two flow domains are not separated. This is made possible by using a mixed moisture/pressure formulation of Richards' equation, and a robust solver with implicit time integration (and modified Picard iterations). For technical numerical aspects, the reader is referred to Ababou and Bagztoglou 1993, Ababou et al. 1992, and references therein.

Both the experimental and numerical results indicate that capillary effects in the unsaturated zone are the cause of the nonlinear and non-harmonic response of the soil column. This can be seen in terms of temporal water table fluctuations $\mathrm{Zs}(\mathrm{t})$ (not shown for lack of space) or in terms of pore pressure profiles $\mathrm{h}(\mathrm{z}, \mathrm{t})$ and temporal evolutions $\mathrm{h}(\mathrm{t})$. Thus, Fig. 13 shows the temporal evolution of measured $h(t)$ at different heights " $\mathrm{z}$ " in the partially saturated sand column, for a given tide machine frequency (Tp). The temporal structure of $h(t)$ at different heights " $\mathrm{z}$ " indicates the following features:

(i) there exists an intermediate region which is intermittently saturated \& de-saturated;

(ii) there is an attenuation of pressure amplitude with height; (iii) there is an increasing phase lag with height (compared to the forcing); and

(iv) the pressure signals $\mathrm{h}(\mathrm{t})$ are non-harmonic and asymmetric (except at the bottom).

The non-harmonic pressure response can be observed in the parts of the column that are intermittently de-saturated, and even more so, permanently unsaturated: the corresponding pressure signals $\mathrm{h}(\mathrm{t})$ are clearly asymmetric, with a sharp rise (shorter wetting phase) and a slower decline (longer drainage phase).

To complete the previous analyzis, vertical profiles of measured hydraulic head $\mathrm{H}(\mathrm{z})$ are shown in Fig. 14 at different times " $t$ " during a single tidal cycle $(t=0$ to $t=T p)$. But first, for easier interpretation of Fig. 14, two facts should be noted: (1) for any fixed height " $z$ ", the time variations of total head $\mathrm{H}(\mathrm{t})$ are equivalent to time variations of pressure head $h(t)$; (2) Darcy's law implies that vertical profiles of total head $(\mathrm{z}, \mathrm{H})$ indicate the direction of flow as follows: a vertical straight line ( | ) signifies no flow; an oblique curve shaped like a "slash" ( / ) signifies downward flow; and an oblique curve shaped like an "anti-slash" $(\backslash)$ signifies upward flow. With this in mind, the results of Fig.14 can be interpreted as follows.

At certain times, the instantaneous total head profiles of Fig. 14 are shaped like broken curves, with 2 zones: upward flow / downward flow. For instance, let us examine the short period experiment $\mathrm{Tp}=10 \mathrm{mn}$.

$\rightarrow$ Diverging upward/downward flow at half cycle $(\mathbf{t}=\mathbf{T} \mathbf{p} / \mathbf{2})$. The $(\mathrm{z}, \mathrm{H})$ profile is a broken curve shaped like " $>$ ". Flow is directed upward $\uparrow$ above height $\mathrm{z}=60 \mathrm{~cm}$, and downward $\downarrow$ below that height. Thus, flow diverges at $\mathrm{z} \approx 60 \mathrm{~cm}$. Also, from other interpretations of tensiometric measurements, it is known that the water table is located just a few cm's above the static level ho $=30 \mathrm{~cm}$, and that it is falling with downward velocity. Thus, downward flow occurs not only at the falling water table $\left(\mathrm{z} \approx 30^{-} \mathrm{cm}\right)$ but also in the "dynamic" capillary zone (from $\mathrm{z} \approx 30^{-} \mathrm{cm}$ to $\mathrm{z} \approx 60 \mathrm{~cm}$ in this case).

$\rightarrow$ Converging upward/downward flow at full cycle $(t=0$ or Tp). At the beginning or end of a cycle $(t=0$ or $t=T p)$, the $(\mathrm{z}, \mathrm{H})$ profile is shaped like " $<$ ", and the situation described previously is reversed. Flow is converging around height $\mathrm{z} \approx 60 \mathrm{~cm}$. The water table is now located just a few cm's below the $30 \mathrm{~cm}$ static level, and it is rising with upward velocity. The column is in a situation of upward flow not only around the rising water table $(\mathrm{z} \approx 30 \mathrm{~cm})$ but also in the "dynamic" capillary zone from $\mathrm{z} \approx 30^{+} \mathrm{cm}$ to $\mathrm{z} \approx 60 \mathrm{~cm}$.

The experimental head profiles $\mathrm{H}(\mathrm{z}, \mathrm{t})$ in Fig.14 can also be used to compare the response of the column to short $v s$. long periods (left: $\mathrm{Tp}=10 \mathrm{mn} /$ right: $\mathrm{Tp}=110 \mathrm{mn}$ ).

$\rightarrow$ Damping. For the short period $\mathrm{Tp}=10 \mathrm{mn}$, pressure head or total head oscillations are completely damped at $\mathrm{z}=80 \mathrm{~cm}$; while for the longer period $\mathrm{Tp}=110 \mathrm{mn}$, pressure is less damped and still fluctuates at $\mathrm{z}=90 \mathrm{~cm}$. Also, the same remark seems to hold for water table amplitudes, or 
for water table maxima. Thus, pressure profiles $\mathrm{h}(\mathrm{z})$ indicate that the maximum height of the oscillatory water table was $\mathrm{z}=41 \mathrm{~cm}$ for $\mathrm{Tp}=10 \mathrm{mn}$, and $\mathrm{z}=46 \mathrm{~cm}$ for $\mathrm{Tp}=110 \mathrm{mn}$ (recall: static height is ho $=30 \mathrm{~cm}$ in both experiments).

$\rightarrow$ Head profile envelope. For $\mathrm{Tp}=10 \mathrm{mn}$ the total head profiles have a narrow envelope, and total head gradients are large (steep profiles). For the longer period $\mathrm{Tp}=110 \mathrm{mn}$, the envelope is more spread out, and the head gradients are relatively low (mild slopes).

$\rightarrow$ Darcy velocity (flux). The previous observations indicate how the oscillatory upward/downward flux through the column is affected by the tidal period (Tp). The flux is related to total head gradient via Darcy's law and permeability (saturated or unsaturated). The steeper head gradients observed for the short tidal period suggest that the oscillatory in/out flux qo(t) at the basis of the column has a larger amplitude for $\mathrm{Tp}=10 \mathrm{mn}$ than for $\mathrm{Tp}=110 \mathrm{mn}$. This interpretation can be summed up as: $\mathrm{A}_{\mathrm{Q} 0}(\mathrm{Tp}=10 \mathrm{mn})>$ $\mathrm{A}_{\mathrm{Q} 0}(\mathrm{Tp}=110 \mathrm{mn})$.

While the amplitude of the Darcy flux $\mathrm{q}_{0}(\mathrm{t})$ was not measured directly, the latter experimental observation was confirmed via numerical simulations as well.

Furthermore, from other analyses of the complete set of tidal machine experiments and from additional simulations, there appeared a clear effect of tidal frequency on the mean water table level (see Alastal et al. for detailed results). The observed effect was a frequency-dependent "underelevation" of the mean water table (temporal mean). For a tidal amplitude Ao $=50 \mathrm{~cm}$ (and a static level of ho $=50 \mathrm{~cm}$ ), the under-elevation can be as much as about $10 \mathrm{~cm}$ or so (mean water table level $\mathrm{Z}=41 \mathrm{~cm}$ instead of the static level ho $=50 \mathrm{~cm}$ ).

At the time of this writing, this under-elevation effect is attributed mainly to capillarity. Indeed, it was found that under-elevation depends not only on tidal frequency, but also on the capillary length of the porous medium (e.g., the $1 / \alpha$ length scale parameter in the Mualem/Van Genuchten model of unsaturated moisture \& permeability curves $v s$. capillary pressure). Finer materials usually have longer capillary lengths. This parameter seems to have an effect on the characteristic forcing period $\mathrm{Tp}^{*}$ for which the maximum under-elevation is obtained (e.g., $\mathrm{Tp}^{*}=81 \mathrm{~s}$ for our experimental "SilicaSand", but $\mathrm{Tp}^{*}=1681 \mathrm{~s}$ for the finer soil known as "Guelph Loam" in the literature).

We end this discussion with a brief note on another ongoing work that is also related to the effects of seawater on a vertical column of porous beach. Thus, Sabbar, Alastal et al. (2013) recently presented some preliminary modeling results on a different coupled phenomenon in a vertical beach profile. It involves forced oscillations of water content and pore pressure in a variably saturated beach column, under the effect of periodic submersion at the top. Vertical flow within the porous beach is driven by oscillating flow at the surface of the beach, due to intermittent egress and recess of waves in the swash zone ("jet de rive" in French). This forcing is quite different from the situations considered in the present paper.

Thus, we have studied the vertical flow induced by slow tidal motions of the sea level, rather than the dynamic effects of intermittent submersions of the beach surface in the swash zone. We have also studied in a simplified way the horizontal propagation of oscillations through a beach forced by incoming waves (in a wave canal). In the real system, slow tidal oscillations of the water table, dynamic wave propagation, and swash zone infiltration/drainage effects are all combined, to various degrees, at different distances from the shore.

\section{REFERENCES}

AвABou R. (2013) - Couplages de modèles en hydrodynamique environnementale \& hydrologie (sols, nappes, rivières, zones côtières). Keynote lecture (paper in French), in Pre-Proc. Internat. Sym p. Sim HE 2013, Ecole Hassania des Travaux Publics, Casablanca, Morocco, 7-8 Nov. 2013. 6 pp

АвавоU R. (2008) - Quantitative Stochastic Hydrogeology: the Heterogeneous Environment. Overexploitation \& Contamination of Shared Groundwater Resources: Management, (Bio) Technological, \& Political Approaches to Avoid Conflicts." NATO-ASI Advanced Studies Institute Series, C.J.G. Darnault (ed.), Springer Sci. \& Business Media BV, Jan. 2008. 119-182

Ababou R., A. Al-Bitar (2008) - Coupled Surface / Subsurface Flow Systems: Numerical Modeling. Overexploitation \& Contamination of Shared Groundwater Resources: Management, (Bio)Technological, \& Political Approaches to Avoid Conflicts. NATO-ASI: Advanced Studies Institute Series, C.J.G. Darnault (ed.), Springer Sci. \& Business Media BV. 105-117

Ababou R., G. Trégarot (2002) — Coupled Modeling of Partially Saturated Flows : Macro-Porous Media, Interfaces, and Variability. Proceedings CMWR 2002, Computational Methods in Water Resources, 23-28 June 2002, Delft, The Netherlands. 8 pp

Ababou R., Tregarot G., Larabi A. (1998) - Partially Saturated Hydrological Flows: Numerical Experiments and Analyses. XII Internat. Proceedings Internat. Conf. on Computational Methods in Water Resources (CMWR), The Chersonese, Crete, Greece, 15-19 June 1998. 8 pp

Ababou R., Tregarot G., Bouzelboudjen M. (1996) - Variably Saturated Subsurface Flow with Layers and Interfaces: Perched Water Tables and Stream-Aquifer Connection. Proceedings ModelCare'96. GWMI Series No.96-OX, Internat. Groundwater Modeling Center (IGWC), Colorado School of Mines, 25-27 Sept. 1996. $10 \mathrm{pp}$

Ababou R., A.C. Bagtzoglou (1993) — "BIGFlOW: A Numerical Code for Simulating Flow in Variably Saturated, Heterogeneous Geologic Media (Theory and User's Manual, Version 1.1)". http:// www.osti.gov/bridge/servlets/purl/10168217-yoTsuT/10168217. pdf. Report NUREG/CR-6028, U.S. Nuclear Regulatory Commission, Gov. Printing Office, Washington D.C. $139 \mathrm{pp}$

Ababou R., Al-Bitar A., Peyrard D., Quintard M., Sanchez Perez J.M., Sauvage S., Vervier P. \& Weng P. (2006) - Modeling coupled surface / subsurface flow interactions : implementation and comparison of three models based on Darcy, Boussinesq / Saint Venant \& Boussinesq/ Diffusive Wave, with application to the Garonne floodplain, Midi-Pyrénées, France”. IPreproc. of Internat. Symp. IAHR-GW 2006 "GroundWater in Complex Environments" (12-14 June 2006, Toulouse, France). Internat. Assoc. Hydraulics Research. Extended abstract, 2 pp

Ababou R., B. Sagar G. Wittmeyer (1992) - Testing Procedures for Spatially Distributed Flow Models. Advances. Water Resources. 15 : 181-198

Ababou R., Marcoux M., Wang Y. (2010) — Experimental and Numerical Study of Hydrodynamic Oscillations in Partially Saturated Porous Media such as Beaches or Dykes”. («Etude expérimentale et numérique des oscillations hydrodynamiques en milieux poreux partiellement saturés tels que plages ou digues»). Actes 7ème Rencontre Hydrodyn. Marine 2010, Univ. Casablanca - Ben M'Sik / Soc. Maroc. Sci. Maritime et Portuaire, Casablanca 24-28 Nov.2010. Keynote Lecture 13 pp

Ababou R., D. Dartus J.-M. Tanguy (2010) - Model Coupling. Mathematical Models (Environmental Hydraulics Series), ISTE \& Wiley, 2010. ISBN 9781848211544.2 pp. 445-491

Ababou R., D. Dartus J.-M. TAnguy (2009) - Couplage de Modèles. Chap.9. Traité d'Hydraulique Environnementale (de la goutte de pluie jusqu'à la mer)», Vol. 4: Modèles mathématiques en hydraulique maritime et modèles de transport. J. M.Tanguy (ed.), Lavoisier (Hermès), Paris, 2009. 281-333 
Alastal K. (2012) - Oscillatory flows and capillary effects in partially saturated and unsaturated porous media: applications to beach hydrodynamics. (Ecoulements oscillatoires et effets capillaires en milieux poreux partiellement saturés et non saturés: applications en hydrodynamique côtière). Doctoral thesis of Institut National Polytech. de Toulouse / Univ. de Toulouse. Institut de Mécanique des Fluides de Toulouse (supervisors. R. Ababou, D. Astruc). Toulouse, France, 16 May 2012. 226 pp

Alastal K., R. Ababou D. Astruc (2011) — Partially saturated oscillatory flow under tidal conditions in homogeneous and layered soil columns (experiment and simulations). DOI: $10.5150 / \mathrm{cmcm} .2011 .024$. PARALIA publisher (http://www.paralia.fr ). On line Https://Docs.Google.Com/ Viewer?Url=Http://Www.Paralia.Fr/Cmcm/E02-24-Alastal.Pdf Proceedings 2nd CM2 Conference (2nd Coastal \& Maritime Mediterranean Conf., Tangiers, Morocco, 22-24 Nov. 2011). 113-118

Alastal K., R. Ababou D. Astruc (2010) — Ecoulements oscillatoires partiellement saturés dans des colonnes de sols homogènes et multicouches. 35èmes Journées du GFHN (Groupement Francophone d'Hydrologie Non saturée) : " Transferts en Milieux Poreux : Hétérogénéité des Processus et des Propriétés ", Université Catholique de Louvain, Louvain-la-Neuve, Belgique, 23-25 novembre 2010. Bulletin GFHN (CEMAGREF publisher), Nov. 2010. 56 : 151154

Al-Bitar A. (2007) - Modélisation des écoulements en milieu poreux hétérogènes $2 \mathrm{D} / 3 \mathrm{D}$, avec couplages surface / souterrain et densitaires. Doctoral thesis of Institut National Polytech. Institut de Mécanique des Fluides de Toulouse. (supervisor: R. Ababou). June 2007, Toulouse, France

BeAvers G.S., D.D. Joseph (1967) - Boundary conditions at naturally permeable wall. Journal of Fluid Mechanics. 30(1) : 197-207

Bedient P. B., C. W. Huber (2002) - Hydrology and Floodplain Analysis. 3rd edition

Brossard J., M. Chagdali V. Rey (2004) - Ecoulement engendré par la houle dans un milieu poreux. Actes VIIIèmes Journées Nat. GCGC Génie Civil-Génie Côtier, Compiègne 7-9 sept.2004. $47-54$

CaO Y.Z., M. GunZburger F. Hua X.M. Wang (2010) - Coupled Stokes-Darcy model with Beavers-Joseph interface boundary condition. Communications in Mathematical Sciences. 8(1) : $1-25$

Cross R.H., Sollitt C.K. (1972) - Wave transmission by overtopping. Proceedings ASCE, Vol. 98, No. WW3. 295-309

DARCY H.P.G. (1856) — Les Fontaines Publiques de la Ville de Dijon, Exposition et Application des Principes à Suivre et des Formules à Employer dans les Questions de Distribution d'Eau. Victor Dalmont éditeur (publisher), Paris, France

Desai C.S, Li G.C. (1983) - A Residual Flow Procedure and Application for Free Surface Flow in Porous Media. Advances in Water Resources. 6(1) : 27-35

FORCHHEIMER P. (1930) - Hydraulik. Teubner Verlaggesellschaft, Stuttgart

Gunduz O., M.M. Aral (2005) - River networks and groundwater flow: a simultaneous solution of a coupled system. $J$. of Hydrology. 34 : 301-216

Hinz C. (1998) - Analysis of unsaturated/saturated water flow near a fluctuating water table. Journal of Contaminant Hydrology. 33 : $59-80$

HoRn D. (2006) - Measurements and modelling of beach groundwater flow in the swash-zone: a review. Continental Shelf Research. 26 : 622-652

Kollet S. J. And Maxwell R. M. (2006) - Integrated surface-groundwater flow modeling: A free-surface overland flow boundary condition in a parallel groundwater flow model. Advances in Water Resources. (29)7 : 945-958
LARABi A., F. De SMEdT (1997) - Numerical solution of a 3D groundwater flow involving free boundaries by a fixed finite element method. J. of Hydrology. 201 : 161-182

Li L., Barry D. A., Stagnitti F., Parlange J.-Y. (2000) Groundwater waves in a coastal aquifer: A new governing equation including vertical effects and capillarity. Water Resour. Res. 36 : 411-420

Li L., Barry D. A., Stagnitti F., Parlange J.-Y., Jeng D. S. (2000) - Beach water table fluctuations due to spring-neap tides: moving boundary effects. Advances in Water Resources. 23 : 817-824

LosadA I.J., M.A. LosadA F.L. Martin (1995) - Experimental study of wave induced flow in a porous structure. Coastal Engineering. 26 : 77-98

Panday S, HuYakorn Ps. (2004) - A fully coupled physically-based spatially-distributed model for evaluating surface/ subsurface flow. Adv. Water Resour. 27 : 361-382

Putti M, PANiconi C. (2004) — Time step and stability control for a coupled model of surface and subsurface flow. Proceedings of the XV International Conference on Computation Methods in Water Resources (CMWR XV), Chapel Hill, NC, USA: Elsevier. 2 : 1391-402

Sabbar M., K. Alastal M. Chagdali R. Ababou (2013) Modélisation d'oscillations forcées de nappes de plages en hydrodynamique côtière: rôle de la zone non saturée. Pre-Proc. Internat. Sym. SimHE 2013, Ecole Hassania Travaux Publics, Casablanca, Morocco, 7-8 Nov. 2013. 6 pp

Sbai M. A., F. De Smedt A. Larabi (2001) - A Generalized Approach for Modeling 3D Transient Free and Moving Boundaries in Coastal Aquifers. Proc. 1rst Internat. Conf. on Saltwater Intrusion and Coastal Aquifers- Monitoring, Modeling \& Management. Essaouira, Morocco, 23-25 April

Sollitt C.K., R.H. Cross (1972) — Wave Reflection and transmission at permeable breakwaters. MIT. Tech. Report No.147, Ralph M. Parsons Lab., Dept. of Civil Engineering, M.I.T., Cambridge, Massachusetts, USA. 147

Tomasicchio G.R., F. D’ALESSANDro (2013) - Wave energy transmission through and over low crested breakwaters. Proc. 12th Internat. Coastal Symposium (Plymouth, England), J. of Coastal Research, Special Issue No. 65 (2013), Conley, D.C., Masselink, G., Russell, P.E. \& O'Hare, T.J. (eds.). 398-403

WANG Y. (2010) - Experimental and Numerical Study of Hydrodynamic Oscillations in Partially Saturated Porous Media. Doctoral thesis. Université de Toulouse / Institut National Polytechnique de Toulouse \& Institut de Mécanique des Fluides de Toulouse. (Thesis supervisors: R. Ababou \& M. Marcoux). Toulouse, France, 16 Sept. 2010. 347pp

Wang Y., R. Ababou M. Marcoux (2012) — Effect and Propagation of Water Level Fluctuations in a Sloping Sandy Beach-Unsaturated Porous Media II: Numerical Simulation Test of Single Harmonic Wave (Long Run). (Proceedings of ICETCE 2012: The 2nd International Conference on Electric Technology and Civil Engineering (18-20 May 2012, Three Gorges, Hubei, China). 5

Wang Y., R. Ababou M. Marcoux (2010) - Signal Processing of Water Level Fluctuations in a Sloping Sandy Beach Modeled in a Laboratory Wave Canal. http://dx.doi. org/10.1061/41103(376)26. Experimental \& Applied Modeling of Unsaturated Soils (GSP202): Proc.2010 GeoShanghai Internat. Conf., Part II: Applied Modeling and Analyses. L.R.Hoyos, X.Zhang, A.J.Puppala (eds.). Amer. Soc. of Civil Engineers: ASCE Geotech. Special Publi. (GSP). 376(41103) : 204210

WARD J.C. (1964) - Turbulent Flow in Porous Media. ASCE Journal of the Hydraulics Division, Proceedings of the ASCE. HY 5 : $1-12$

Weng P., Sanchez-Perez J.M., Sauvage S., Vervier P., Giraud F. (2003) - Hydrological modelling to characterize the riparian wetland of a large alluvial river (Garonne river, France). Hydrological Processes. 17 : 2375-2392 